UNIVERSIDADE FEDERAL DO RIO GRANDE DO SUL

HOSPITAL DE CLÍNICAS DE PORTO ALEGRE RESIDÊNCIA EM ÁREA PROFISSIONAL DE SAÚDE

PROGRAMA DE RESIDÊNCIA EM ENFERMAGEM OBSTÉTRICA

Márcia Cordeiro da Cunha

COMPETÊNCIAS ESSENCIAIS PARA PRÁTICA DA ENFERMAGEM OBSTÉTRICA: REVISÃO INTEGRATIVA

Porto Alegre

2021 
UNIVERSIDADE FEDERAL DO RIO GRANDE DO SUL

HOSPITAL DE CLÍNICAS DE PORTO ALEGRE RESIDÊNCIA EM ÁREA PROFISSIONAL DE SAÚDE

PROGRAMA DE RESIDÊNCIA EM ENFERMAGEM OBSTÉTRICA

Márcia Cordeiro da Cunha

\section{COMPETÊNCIAS ESSENCIAIS PARA PRÁTICA DA ENFERMAGEM OBSTÉTRICA: REVISÃO INTEGRATIVA}

Trabalho de Conclusão de Residência desenvolvido como requisito parcial para obtenção de título de especialista em Enfermagem Obstétrica pela Residência Multiprofissional em Saúde do Hospital de Clínicas de Porto Alegre.

Orientadora: $\operatorname{Prof}^{\mathrm{a}} \operatorname{Dr}^{\mathrm{a}}$ Enf $^{\mathrm{a}}$ Letícia Becker Vieira Co-orientadora: Dr ${ }^{\mathrm{a}}$ Enf $^{\mathrm{a}}$ Laura Leismann de Oliveira

Porto Alegre 


\section{LISTA DE ABREVIATURAS}

ABENFO Associação Brasileira de Obstetrizes e Enfermeiros Obstetras

APICE ON Aprimoramento e Inovação no Cuidado e Ensino em Obstetrícia e Neonatologia

CEP Comitê de Ética em Pesquisa

COFEN Conselho Federal de Enfermagem

CNES Cadastro Nacional de Estabelecimentos de Saúde

EO Enfermeira Obstétrica

HCPA Hospital de Clínicas de Porto Alegre

ICM International Confederation of Midwives / Confederação Internacional das Parteiras

LILACS Literatura Latino-Americana e do Caribe em Ciências da Saúde

OMS Organização Mundial de Saúde

SUS Sistema Único de Saúde

TNICE Tecnologias não invasivas de cuidado de enfermagem obstétrica

UFRGS Universidade Federal de Ciências da Saúde de Porto Alegre 


\section{SUMÁRIO}

1 INTRODUÇÃO 5

2 REVISÃO BIBLIOGRÁFICA

2.1 ATUAÇÃO DA ENFERMAGEM OBSTÉTRICA NO BRASIL 7

2.2 PROJETO APICE ON 8

2.3 COMPETÊNCIAS PROFISSIONAIS DA ENFERMEIRA OBSTÉTRICA 10

3 OBJETIVOS 12

4 PERCURSO METODOLÓGICO 13

4.1 REVISÃO INTEGRATIVA 13

4.2 QUESTÃO DE PESQUISA 13

4.3 BUSCA NA LITERATURA 13

4.4 CATEGORIZAÇÃO DOS ESTUDOS 14

4.5 AVALIAÇÃO DOS ESTUDOS INCLUÍDOS NA REVISÃO 14

4.6 INTERPRETAÇÃO DOS RESULTADOS E APRESENTAÇÃO DA REVISÃO $\begin{array}{ll}\text { INTEGRATIVA } & 14\end{array}$

$\begin{array}{lll}4.7 & \text { ASPECTOS ÉTICOS } & 14\end{array}$

5 RESULTADOS 15

6 CONSIDERAÇÕES FINAIS 29

$\begin{array}{ll}\text { REFERENCIAS } & 30\end{array}$ 


\section{INTRODUÇÃO}

A maioria dos países ocidentais, e entre eles inclui-se o Brasil, legitima o modelo de assistência obstétrica e neonatal médico, caracterizado pela visão do nascimento como uma patologia. O corpo da mulher dentro dessa lógica de assistência medicalizada transforma-se numa máquina incompleta e que necessita de tecnologias sofisticadas, quase sempre utilizadas sem devida avaliação acerca de sua segurança, para que consiga parir (BRASIL, 2014). Acredita-se que o modelo biomédico de assistência obstétrica e neonatal, aliado a utilização do conhecimento técnico de maneira acrítica pode contribuir para o aumento de riscos para mulheres e crianças durante o trabalho de parto, parto e puerpério e podem, até mesmo, serem fatores determinantes de morbimortalidade materna e neonatal. A busca por um modelo assistencial que esteja voltado para a integralidade das necessidades de saúde dos indivíduos e que supere as dificuldades causadas pela hegemonia do modelo biomédico e tecnicista é um dos grandes desafios do sistema de saúde brasileiro (FERTONANI, 2015).

Considerando a atenção obstétrica no país, para se buscar experiências de parto humanizadas, seguras e com práticas baseadas em evidência é importante que haja uma reflexão acerca da importância do parto como evento fisiológico e social. Uma visão compreensiva da história de vida das mulheres, dos valores e da fisiologia humana pode ajudar profissionais a se afastarem do modelo biomédico vigente. A enfermagem é uma das profissões que tem condição de atuar junto às mulheres que buscam atendimento em serviços de saúde para assistência ao parto, dando segurança e ajudando nesse momento significativo e único, ao atuar de maneira humanizada, valorizando a fisiologia do parto e nascimento (JONES, 2008).

O que se constata em estudos a respeito da atenção obstétrica brasileira é que evidências científicas isoladamente não servem para mudança no modelo assistencial medicalizado e intervencionista ao parto de risco habitual (NARCHI, 2010), e que para que isso ocorra, é necessária a reformulação dos espaços de saúde, que os recursos tecnológicos sejam adequadamente alocados, bem como aprimoramento dos profissionais que prestam assistência obstétrica.

A partir do ano de 1998, o Ministério da Saúde, junto a secretarias municipais e estaduais, vem ampliando a destinação de recursos voltados para formação de enfermeiras obstétricas a fim de inserir essas profissionais na assistência ao parto (RIESCO E FONSECA, 2002). Os investimentos se justificam por experiências positivas de atuação dessas profissionais mundialmente, não só com resultados positivos de satisfação com a assistência prestada, mas, principalmente, quando se considera a redução de taxas de intervenções desnecessárias e 
cesarianas (AMORIM E GUALDA, 2011).

Quanto às modalidades de formação em enfermagem obstétrica, no ano de 2009, a Portaria Interministerial n ${ }^{\circ} 1.077$ implementa os Programas de Residência Multiprofissional em Saúde e a Residência em Área Profissional da Saúde e estabelece a especialização no modelo de ensino em serviço na modalidade lato sensu (BRASIL, 2009). Posteriormente, no ano de 2011, o Ministério da Saúde lança a estratégia Rede Cegonha, que entre diversas iniciativas aumentou o número de programas de residência nessa área, para a ampliação da atuação da enfermeira obstétrica (EO) com o objetivo de prover cuidados integrais e seguros para mulheres e recém-nascidos,

No cenário do Hospital de Clínicas de Porto Alegre (HCPA), o Programa de Residência em Enfermagem Obstétrica surge a partir da pactuação da instituição tanto a Rede Cegonha, quanto ao projeto de Aprimoramento e Inovação do Cuidado e Ensino em Obstetrícia e Neonatologia (Apice ON), com o objetivo de especializar enfermeiros na modalidade de ensino em serviço seguindo princípios e diretrizes do Sistema Único de Saúde (SUS) (UFRGS, 2017).

A formação em serviço é uma das modalidades de formação da enfermeira obstétrica, e existem competências internacionalmente recomendadas para formação desse profissional. A Confederação Internacional de Obstetrizes (International Confederation of Midwives - ICM) propõe competências essenciais para a prática da obstetrícia por esses profissionais e apresenta um conjunto mínimo de conhecimentos, habilidades e comportamentos necessários para a prática profissional (ICM, 2019) que podem ser utilizadas para avaliar o desempenho de organizações e programas de formação profissional (KAK, BURKHALTER E COOPER, 2001),

Portanto, conhecer a produção científica dos últimos anos acerca das competências essenciais e a relação desses estudos com diretrizes internacionais se torna relevante. Além disso, aprofundar tais conhecimentos pode contribuir com o processo avaliativo de residentes de um programa de residência em enfermagem obstétrica, especificamente, a realidade da Residência em Enfermagem Obstétrica do HCPA.

No momento, o Programa de Residência em Enfermagem Obstétrica do HCPA não possui uma definição formal do conjunto de competências essenciais e habilidades a serem desenvolvidas por seus residentes, e nisso cabe a finalidade desse projeto, com o intuito de contribuir com uma demanda do Programa. Considerando esse cenário, o presente trabalho de conclusão buscou responder através da condução de uma revisão integrativa de literatura a seguinte pergunta: quais as competências essenciais para prática da enfermagem obstétrica 
encontradas na literatura nos últimos 10 anos? 


\section{REVISÃO BIBLIOGRÁFICA}

\subsection{ATUAÇÃO DA ENFERMAGEM OBSTÉTRICA NO BRASIL}

A história das políticas públicas de saúde no Brasil é intimamente ligada às mudanças na atenção obstétrica e a inserção da enfermeira na atenção ao parto e ao nascimento (AMORIM E GUALDA, 2011). Atualmente, no Brasil, existem duas modalidades reconhecidas de profissionais não-médicos que atuam na assistência ao parto: as obstetrizes (com formação por cursos de entrada direta) e enfermeiras obstétricas (enfermeiras de formação com curso de especialização ou residência em obstetrícia, ou na área materno-infantil ou ainda, aquelas que realizaram a prova de certificação e titulação).

Além desses termos, é comum ouvir o termo em inglês midwife, que se refere a parteira profissional (CINTRA E RIESCO, 2019). Para fim de adaptação à realidade brasileira a Associação Brasileira de Obstetrizes e Enfermeiros Obstetras (ABENFO) considera que o termo "parteira profissional" deve ser compreendido como sinônimo de enfermeira obstétrica e obstetriz (ABENFO, 2002). A atuação dessas profissionais é amparada pela Lei do Exercício Profissional de Enfermagem de 1986, que dispõe sobre a regulamentação do exercício da enfermagem em território brasileiro e condiciona a atuação dessa profissional a inscrição sob o Conselho Federal de Enfermagem (BRASIL, 1986).

Posteriormente, outros marcos regulatórios foram incluídos na legislação brasileira para garantir a legitimidade da atuação da enfermeira obstétrica. Considerando o estabelecimento do SUS no início da década de 90 e a necessidade de descrição dos procedimentos realizados dentro das instituições de saúde do país na Tabela do Sistema de Informações Hospitalares do Sistema Único de Saúde (SIH-SUS), o procedimento do parto normal sem distócia realizado por enfermeiro obstetra passa a ser reconhecido para fins de cobrança nacionalmente apenas no fim da década de 90 (BRASIL, 1998).

Mais recentemente, a Resolução do Conselho Federal de Enfermagem (COFEN) no 477 do ano de 2015 detalha as atribuições privativas do enfermeiro especialista em enfermagem obstétrica. Nesta está descrita a realização de cuidados de enfermagem de maior complexidade técnica, ligada à área de obstetrícia, que exijam conhecimentos científicos e capacidade de tomar decisões imediatas, além de atividades previstas a enfermeira obstétrica como membro das equipes de saúde como a assistência à parturiente e ao parto normal e execução do parto sem distócia (COFEN, 2015).

A prática da enfermeira obstétrica na atenção ao parto, majoritariamente, é voltada a valorização da mulher, tratando-a com respeito e fortalecendo o protagonismo da figura 
feminina no processo de parir (CAUS ET AL, 2012). Considerando essa característica da prática da EO, o ambiente hospitalar de atenção ao parto vem sofrendo reformulações, muito discutidas e preconizadas por políticas públicas de saúde e recomendações internacionais que reforçam a inclusão de profissionais não-médicos na assistência ao parto e voltam-se para perspectiva de humanização da assistência (BRASIL, 2014).

Nesse contexto de busca por consolidação e reconhecimento da capacidade profissional para atuar nesses espaços, as enfermeiras obstétricas usam de tecnologias não invasivas de cuidado (TNICE) de enfermagem obstétrica, que focam no parto como um processo fisiológico no ciclo reprodutivo das mulheres (VARGENS, SILVA E PROGIANTI, 2013). Recomendações das atuais Diretrizes de Assistência ao Parto Normal no Brasil destacam que, um modelo de assistência voltado para atuação da enfermeira obstétrica pode representar maior custo-efetividade pela redução de intervenções na prática obstétrica e uso racional dos recursos humanos da área da saúde (BRASIL, 2016). Dessa forma, algumas estratégias para ampliação da atuação dessas profissionais são implementadas nos serviços de saúde, entre elas, o projeto Apice ON.

\subsection{PROJETO APICE ON}

A Residência em Área Profissional de Saúde em Enfermagem Obstétrica do Hospital de Clínicas de Porto Alegre (HCPA) surge a partir de uma iniciativa do Ministério da Saúde, vinculado a universidades federais, Ministério da Educação e associações da sociedade civil que culminou na criação do projeto de Aprimoramento e Inovação do Cuidado e Ensino em Obstetrícia e Neonatologia (Apice ON). Dentre os objetivos específicos deste projeto, inclui-se o de qualificar o ensino e o exercício da obstetrícia, com base na garantia de direito dos indivíduos e no uso de evidências científicas. Ainda prevê linhas de investimento em formação profissional, entre elas a especialização e aprimoramento em Enfermagem Obstétrica (UFMG, 2019).

O projeto Apice ON funciona como uma estratégia de indução, articulação de ações e qualificação dos serviços (principalmente hospitais de ensino) a fim de torná-los referência nas boas práticas de atenção ao nascimento, planejamento reprodutivo pós-parto e pós-aborto, atenção às mulheres em situações de violência sexual, de abortamento e aborto legal. $\mathrm{O}$ foco na atuação em hospitais vinculados a universidades se justifica pelo fato de que esses espaços são mais adequados para disparo de mudanças na atenção em saúde, servindo como indutor de práticas e espelho para outras instituições de saúde (BRASIL, 2017). Cabe ressaltar que apesar de resultados positivos de mudanças em práticas na assistência ao parto acontecerem com 
frequência em hospitais de ensino, não se pode afirmar que as boas práticas estejam consolidadas nesses cenários (UFMG, 2019).

O Apice ON é composto por três componentes: Atenção, Ensino/Formação e Gestão. A residência em Enfermagem Obstétrica do HCPA se enquadra como uma ferramenta para alcance do objetivo de Ensino/Formação que prevê a criação de programas de integração ensino e serviço, formalizado por meio de contrato entre as instituições de ensino superior, o gestor do sistema de saúde e a direção do hospital (BRASIL, 2017). De acordo com a literatura, a inserção da enfermeira na atenção ao parto de risco habitual necessita de estratégias de apoio para sua concretização e se considera que a decisão política de incluir profissionais não-médicos nesse espaço acarreta em disputa dentro do mercado da assistência obstétrica, demandando sensibilização dos atores envolvidos na efetivação da assistência adequada às mulheres (DIAS E DOMINGUES, 2005).

A inserção da enfermeira no momento do parto, conforme preconizado pelas políticas públicas de saúde do país, representa uma mudança no modelo de atenção que demanda mudanças nas estruturas das unidades de saúde, mudanças no pensamento dos profissionais e deve ocorrer, principalmente, como uma mudança da política institucional (AMARAL ET AL, 2019).

Considerando a realidade do Programa de Enfermagem Obstétrica no HCPA, um documento que contempla a Proposta de Protocolo de Assistência Compartilhada ao Parto está sendo construído e conta com a colaboração de enfermeiras, médicos e gestores ligados ao serviço de ginecologia e obstetrícia, pediatria e serviço de enfermagem materno-infantil. Nesse documento, serão pactuados os detalhes da assistência no Modelo Colaborativo de atenção ao parto e nascimento nessa instituição. O modelo colaborativo na realidade hospitalar representa interação do médico obstetra e da enfermeira obstétrica na equipe, com pronta referência ao profissional médico no caso de detecção de complicações em partos de risco habitual assistidos pela enfermeira (VOGT, SILVA E DIAS, 2014). A colaboração entre profissionais de saúde é um processo dinâmico e ativo e que normalmente está associado ao alcance de um objetivo em comum, no caso da obstetrícia, o objetivo de prover cuidado seguro e efetivo no cuidado das mulheres e suas famílias (DOWNE, FINLAYSON E FLEMING, 2010).

No contexto brasileiro de atenção ao parto, nem sempre a colaboração entre a categoria médica e a enfermagem ocorre de forma efetiva, e isso pode se relacionar ao fato de haver desconhecimento a respeito das habilidades de profissionais não-médicos na atenção ao parto, número insuficiente de enfermeiras obstétricas atuando nesses espaços, conflitos pessoais entre 
os profissionais e falta de união e fortalecimento da categoria profissional (NARCHI, 2010). Um estudo realizado no HCPA que contou com a contribuição de enfermeiras obstétricas que atuavam na instituição, evidenciou que uma das barreiras para desenvolvimento da competência técnica da enfermeira para atenção ao parto, nesse ambiente, era a falta de espaço para prática, especificamente, a centralização do modelo de assistência obstétrica exclusivamente médico (RABELO E OLIVEIRA, 2010).

Em um contexto similar ao desse estudo, conduzido há 13 anos, se encontrava a atenção obstétrica no HCPA no momento da pactuação com o projeto Apice ON, em 2017. O projeto Apice ON surge como estratégia para fortalecimento da atuação da EO e consequente atenção integral à parturiente, com uso de tecnologias adequadamente empregadas na assistência à mulher. Considerando a necessidade de qualificação dos profissionais de enfermagem através da formação em serviço, cabe a análise das competências profissionais pertinentes à EO.

\subsection{COMPETÊNCIAS PROFISSIONAIS DA ENFERMEIRA OBSTÉTRICA}

De acordo com a Organização Mundial de Saúde (OMS) considera-se que o profissional que atende a partos de forma segura deve ser treinado a partir de programas de educação que permitam o desenvolvimento das habilidades necessárias para acompanhamento da gravidez, partos normais e puerpério imediato (WHO, 2004).

A Confederação Internacional das Parteiras (ICM) é uma organização não governamental que representa associações de parteiras profissionais em 115 países mundialmente. Essa organização atua com a finalidade de atingir objetivos comuns no cuidado às mulheres e recém-nascidos, entre eles, a qualificação da atenção ao nascimento. No ano de 2019 foi publicado um documento que atualiza a relação de competências essenciais preconizadas mundialmente para a prática da obstetrícia, descrevendo conhecimentos, habilidades e comportamentos profissionais mínimos que devem ser desenvolvidos nos programas de educação para que o indivíduo seja considerado uma parteira profissional certificada, conforme a definição da organização (ICM, 2018; ICM, 2019).

As competências descritas e validadas por especialistas em todo o mundo têm a finalidade de servir de base para programas de formação em enfermagem obstétrica, dar instruções claras sobre o exercício da profissão, auxiliar professores com relação às destrezas necessárias a parteira profissional e servir de marco regulatório para auxílio na tomada de decisão por gestores quanto a prática profissional (OPAS, 2013).

De forma geral, a competência profissional pode ser definida como a forma de se produzir resultados desejáveis a partir da habilidade para executar uma tarefa específica 
(CUNHA ET AL, 2009) e é considerada como um marco no desenvolvimento profissional, acompanhada da proficiência adquirida a partir de anos de experiência na área (KAK, BURKHALTER E COOPER, 2001).

Na realidade de um programa de especialização de profissionais de saúde, é importante considerar que a competência profissional se relaciona ao desempenho desse profissional, mas não são sinônimos. O desempenho profissional se caracteriza pelas ações do sujeito no seu contexto real de prática. Este desempenho é determinado pela capacidade adquirida de acordo com o alcance das competências da profissão (OPAS, 2013).

Dessa forma, as competências essenciais para prática da enfermagem obstétrica são sensíveis aos diferentes cenários que essas profissionais atuam, sendo relevante revisar e/ou modificar os enunciados das competências para estarem em consonância com a realidade em questão. 


\section{OBJETIVOS}

Analisar a produção de conhecimento científico no mundo a respeito das competências essenciais para prática profissional da enfermagem obstétrica. 


\section{PERCURSO METOdológico}

\subsection{REVISÃO INTEGRATIVA}

Trata-se de um estudo descritivo, que visa conhecer as competências essenciais necessárias para a formação da enfermeira obstétrica. A pesquisa descritiva exige do pesquisador uma série de informações prévias a respeito de determinado fenômeno (UFRGS, 2009), nesse caso específico, o conjunto de competências essenciais para prática da obstetrícia, que foi investigado numa revisão integrativa da literatura e discutido com documentos nacionais e internacionais. Esta metodologia de pesquisa permite a síntese dos conhecimentos produzidos a respeito de uma temática e permite o estabelecimento de conclusões gerais sobre campo de estudo em questão (MENDES, SILVEIRA E GALVÃO, 2008).

A revisão integrativa foi composta de seis etapas: estabelecimento da questão de pesquisa, busca na literatura, categorização dos estudos encontrados (de acordo com os critérios de inclusão e exclusão estabelecidos), avaliação dos estudos selecionados, interpretação dos resultados e apresentação da revisão (MENDES, SILVEIRA E GALVÃO, 2008).

\subsection{QUESTÃO DE PESQUISA}

Considerando o tema proposto e objetivo da pesquisa, a formulação do problema de pesquisa se baseia na questão norteadora: quais as competências essenciais para prática da enfermagem obstétrica encontradas na literatura nos últimos 10 anos?

Para isso, foram selecionadas as palavras-chave para execução da busca por estudos, os Descritores em Ciência da Saúde (DeCS) da Bireme: "competência profissional”, "enfermeira obstétrica" ou "enfermagem obstétrica e os descritores MeSH (Medical Subject Headings) "professional competence" e "midwifery", além de termos relacionados. Foram utilizados os operadores booleanos "and" e "or" para cruzamento dos termos na busca.

\subsection{BUSCA NA LITERATURA}

A busca na literatura deu-se na Biblioteca Virtual em Saúde na base de dados eletrônica Literatura Latino-Americana e do Caribe em Ciências da Saúde (LILACS) e na PubMed. Foram incluídos artigos originais de pesquisa, revisão ou reflexão, disponíveis integralmente de forma eletrônica, publicados em qualquer idioma, entre os anos de 2011 e 2020. Foram excluídos editoriais, cartas, comentários, publicações duplicadas em mais de uma base de dados ou que não respondessem à questão norteadora do estudo.

A seleção dos artigos a serem incluídos na pesquisa deu-se a partir da pesquisa por descritores nas bases de dados selecionadas, leitura do conteúdo do resumo e título da totalidade dos artigos encontrados, aqueles que responderem a questão de pesquisa, leitura na íntegra dos 
artigos, para então, determinação dos artigos que foram incluídos na revisão.

\subsection{CATEGORIZAÇÃO DOS ESTUDOS}

Nesta etapa de revisão, os estudos incluídos foram revisados quanto ao seu conteúdo, informações-chave e nível de evidência. Foi criado um banco de dados que contou com as informações necessárias para revisão dos artigos, incluindo informações como: sujeitos de pesquisa, objetivo do estudo, metodologia empregada, resultados, conclusões e observações gerais. Um instrumento de coleta dessas informações foi utilizado para facilitar a análise (APÊNDICE A).

\subsection{AVALIAÇÃO DOS ESTUDOS INCLUÍDOS NA REVISÃO}

Nesta etapa da revisão foi realizada uma análise crítica dos estudos selecionados, comparando achados dos diferentes estudos e procurando explicações para resultados conflitantes, se encontrados (MENDES, SILVEIRA E GALVÃO, 2008). Nesta etapa pode haver exclusão de artigos, caso nas etapas anteriores ainda não se tivesse identificado divergência com o objetivo proposto.

A coleta de dados se deu no mês de julho de 2020, retornou um total de 352 artigos, desses, todos tiveram o título e resumo lidos para avaliar a pertinência com a questão norteadora do estudo. Dos estudos incluídos na revisão, após leitura de título e resumo, 28 artigos foram lidos na íntegra, resultando na amostra final composta de nove artigos que foram incorporados à análise, conforme a Figura 1.

Figura 1 - Diagrama da aplicação de filtros de pesquisa, limites e critérios de inclusão.

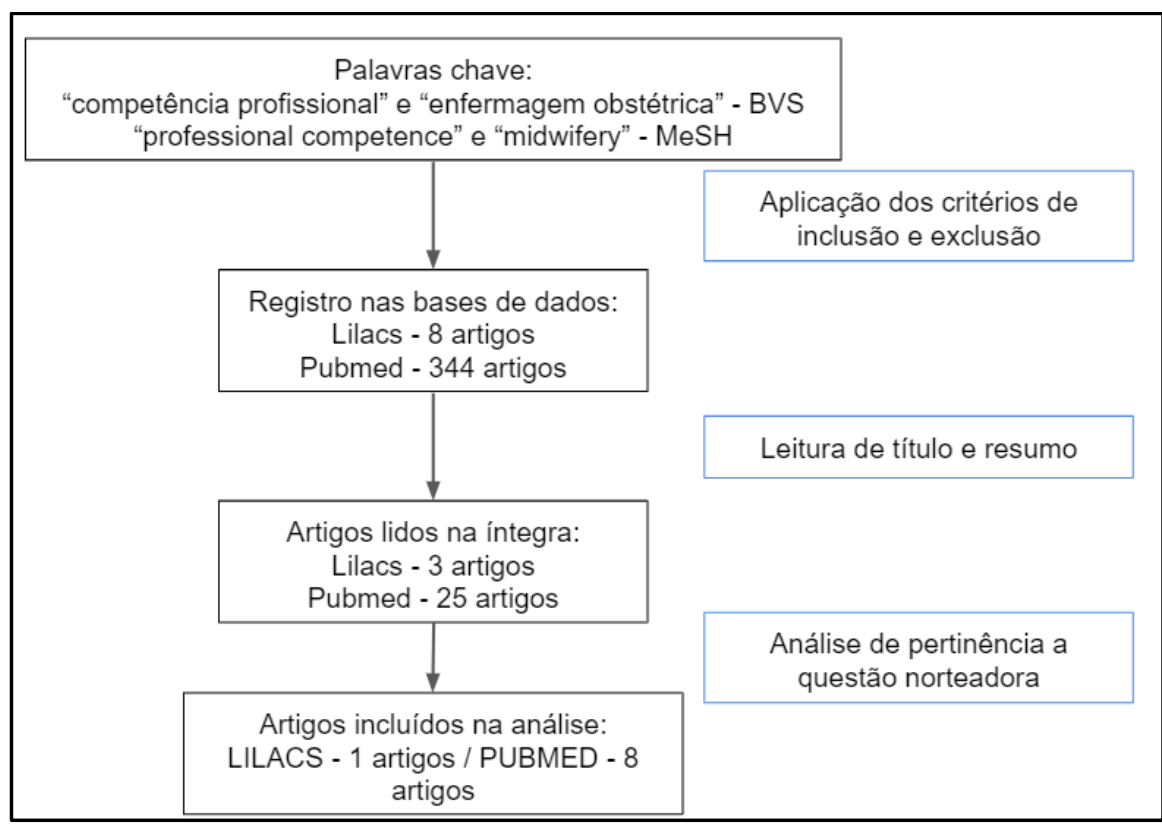

Fonte: Autora, 2020. 
Para análise dos artigos incluídos na revisão foi criada uma ficha de extração de dados com as variáveis: título, autoria, periódico e ano de publicação, objetivos, tipo de estudo, amostra/população, local/campo de estudo, coleta de dados, resultados e conclusões. No Quadro 1, as principais informações extraídas dos estudos primários incluídos na revisão foram apresentadas.

\subsection{INTERPRETAÇÃO DOS RESULTADOS E APRESENTAÇÃO DA REVISÃO INTEGRATIVA}

Nesta etapa, há a síntese crítica dos estudos incluídos, identificação de conclusões e implicações da revisão, identificação de possíveis lacunas e proposição de sugestões para pesquisas futuras. Os resultados da revisão integrativa serão apresentados no formato de manuscrito de artigo científico a ser submetido a período.

\subsection{ASPECTOS ÉTICOS}

Quanto aos aspectos éticos do presente estudo, foram respeitados os direitos autorais e de conteúdo dos estudos utilizados na revisão, bem como na discussão dos resultados encontrados.

\section{RESULTADOS}

Os resultados da revisão conduzida neste trabalho de conclusão de curso serão apresentados no formato de artigo científico, conforme as normas da revista científica Journal of Nursing and Health (JONAH). Especificações e detalhes sobre as normas editoriais do periódico estão detalhadas na página eletrônica da revista (JONAH, 2020). 
REVISÃO INTEGRATIVA

\author{
Competências essenciais para prática da enfermagem obstétrica: revisão \\ integrativa
}

Essential competencies for midwifery practice: integrative review

Competencias esenciales para la practica de la parteria: revisión integrativa

\author{
Márcia Cordeiro da CUNHA ${ }^{1}$; Letícia Becker VIEIRA²; \\ Laura Leismann de OLIVEIRA ${ }^{3}$
}

\begin{abstract}
Resumo
Objetivo: Analisar através de uma revisão integrativa de literatura a produção de conhecimento científico a respeito das competências essenciais para prática profissional da enfermagem obstétrica. Método: Trata-se de uma revisão integrativa de literatura. Foram buscados nas bases de dados LILACS e PUBMED os termos "competência profissional" e "enfermagem obstétricas", retornando um total de 352 artigos, desses, nove foram incluídos na análise após revisão de critérios de inclusão. Resultados: grande parte dos estudos relacionou maior competência profissional com experiências práticas variadas, campos de formação com instrutores qualificados, onde a autonomia profissional pode ser desenvolvida. Conclusões: Falta de competência profissional adequada aumenta riscos para segurança do paciente, influencia de forma negativa na confiança pública na profissão e nos sistemas de saúde e ainda prejudica indicadores de qualidade na assistência materna e neonatal. Parte da dificuldade para aprimoramento e atuação de enfermeiras obstétricas se dá pela inserção insuficiente da profissional no parto e nascimento.
\end{abstract}

Descritores: Enfermeira obstétrica; Competência profissional; Enfermagem obstétrica.

\begin{abstract}
Objective: To analyze, through an integrative literature review, the production of scientific knowledge regarding the essential competencies for professional practice in obstetric nursing. Method: This is an integrative literature review. The terms "professional competence" and "midwifery" were searched in the LILACS and PUBMED databases, returning a total of 352 articles, of which nine were included in the analysis after reviewing the inclusion criteria. Results: most of the studies related greater professional competence to varied practical experiences, training fields with qualified instructors, where professional autonomy could be developed. Conclusions: Lack of adequate professional competence increases risks for patient safety, negatively influences public confidence in the profession and health systems, and also impairs quality indicators in maternal and neonatal care. Part of the difficulty for improvement and performance of obstetric nurses is due to the insufficient insertion of the professional in childbirth and birth.
\end{abstract}

Descriptors: Midwife; Professional competence; midwifery.

\title{
Resumen
}

Objetivo: Analizar, a través de una revisión integradora de la literatura, la producción de conocimiento científico en el mundo sobre las habilidades esenciales para la práctica profesional en enfermería obstétrica. Método: Se trata de una revisión bibliográfica integradora. Los términos "competencia profesional" y "enfermería obstétrica" fueron buscados en las bases de datos LILACS y PUBMED, arrojando un total de 352 artículos, de los cuales nueve fueron incluidos en el análisis luego de revisar los criterios de inclusión. Resultados: la mayoría de los estudios relacionan mayor competencia profesional con variadas experiencias prácticas, campos de formación con instructores 
calificados, donde se puede desarrollar la autonomía profesional. Conclusiones: La falta de competencia profesional adecuada aumenta los riesgos para la seguridad del paciente, influye negativamente en la confianza del público en la profesión y los sistemas de salud y también deteriora los indicadores de calidad en la atención materna y neonatal. Parte de la dificultad de superación y desempeño de las enfermeras obstétricas se debe a la insuficiente inserción del profesional en el parto y el parto.

Descriptores: Enfermera obstétrica; Competencia profesional; Enfermería obstétrica.

${ }^{1}$ Enfermeira, Residente em Enfermagem Obstétrica no Hospital de Clínicas de Porto Alegre.

${ }^{2}$ Enfermeira, Doutora em Enfermagem pela Escola de Enfermagem Anna Nery da Universidade Federal do Rio de Janeiro, Professora Adjunta da Escola de Enfermagem da Universidade Federal do Rio Grande do Sul. Professora Permanente do Programa de Pós Graduação em Enfermagem PPGEnf/UFRGS. Especialista em Gênero e Sexualidade UERJ. Especialista em Gestão em Enfermagem UNIFESP/SP.

${ }^{3}$ Enfermeira, Doutora em Enfermagem pela Universidade Federal do Rio Grande do Sul (UFRGS), enfermeira obstetra atuante no Hospital de Clínicas de Porto Alegre (HCPA), preceptora do Programa de Residência em Enfermagem Obstétrica do HCPA.

\section{INTRODUÇÃO}

A assistência obstétrica no Brasil nos últimos anos, mesmo impulsionada por políticas públicas que pautam a humanização dos cuidados à mulher, ao recémnascido e sua família, ainda enfrenta dificuldades para superar o modelo medicalizado tradicional que historicamente se estruturou no país. ${ }^{1} 0$ modelo biomédico de assistência obstétrica, aliado a utilização do conhecimento técnico de maneira pouco crítica, podem contribuir para o aumento de riscos para mulheres e crianças durante o trabalho de parto e nascimento e podem, até mesmo, serem fatores determinantes de morbimortalidade materna e neonatal. A maioria dos países ocidentais, e entre eles inclui-se o Brasil, legitima o modelo de assistência obstétrica e neonatal centrado na figura do médico, caracterizado pela visão do nascimento como uma patologia. Nessa lógica de assistência medicalizada, o corpo da mulher reduz-se numa máquina incompleta, na qual necessita de tecnologias sofisticadas, quase sempre utilizadas sem devida avaliação acerca de sua segurança, para que consiga parir. ${ }^{2}$

A busca por um modelo assistencial que esteja voltado para a integralidade das necessidades de saúde dos indivíduos e que supere as dificuldades causadas pela hegemonia do modelo biomédico e tecnicista é um dos grandes desafios do sistema de saúde brasileiro. ${ }^{3} \mathrm{O}$ que se constata, em estudos a respeito da atenção obstétrica brasileira, é que evidências científicas isoladamente não servem para mudança no modelo assistencial medicalizado e intervencionista ao parto de risco habitual, ${ }^{4} \mathrm{e}$ que para que isso ocorra, é necessária a reformulação dos espaços de saúde e que os 
recursos tecnológicos sejam adequadamente alocados. Dentre as estratégias para mudança do modelo assistencial em obstetrícia predominante, a formação e inclusão de profissionais não-médicos na assistência ao parto vem sendo discutida ao longo dos anos.

Desde 1998, o Ministério da Saúde, junto às secretarias municipais e estaduais, vem ampliando a destinação de recursos voltados para formação de enfermeiras obstétricas, a fim de inserir essas profissionais na assistência ao parto. ${ }^{5}$ Os investimentos se justificam por experiências positivas de atuação dessas profissionais mundialmente, não só com resultados positivos de satisfação com a assistência prestada, mas, principalmente, quando se considera a redução de taxas de intervenções desnecessárias e cesarianas. ${ }^{6}$

Atualmente no Brasil existem duas modalidades reconhecidas de profissionais não-médicos que atuam na assistência ao parto: as obstetrizes (com formação por cursos de entrada direta) e enfermeiras obstétricas (enfermeiras de formação com curso de especialização ou residência em obstetrícia, ou na área materno-infantil ou ainda, aquelas que realizaram a prova de certificação e titulação). Além desses, é comum ouvir o termo em inglês midwife, que se refere a parteira profissional. ${ }^{7}$ Para fim de adaptação à realidade brasileira a Associação Brasileira de Obstetrizes e Enfermeiros Obstetras (ABENFO) considera que o termo "parteira profissional” deve ser compreendido como sinônimo de enfermeira obstétrica e obstetriz. ${ }^{8}$ A atuação dessas profissionais é amparada pela Lei do Exercício Profissional de Enfermagem de 1986, que dispõe sobre a regulamentação do exercício da enfermagem em território brasileiro e condiciona a atuação dessa profissional a inscrição sob o Conselho Federal de Enfermagem. ${ }^{9}$

A prática da enfermeira obstétrica na atenção ao parto, majoritariamente, é voltada à valorização da mulher, tratando-a com respeito e fortalecendo a figura feminina no processo de parir. ${ }^{10}$ Considerando essa característica da assistência, 0 ambiente hospitalar de atenção ao parto vem sofrendo reformulações, fundamentadas por políticas públicas de saúde e recomendações internacionais que reforçam a inclusão de profissionais não-médicos na assistência ao parto e voltam-se para perspectiva de humanização da assistência. ${ }^{2}$ Quanto à formação desses profissionais para assistência ao parto, há de se considerar a existência de 
competências internacionalmente propostas para formação, que incluem a avaliação individual e de desempenho de organizações e programas de formação profissional. ${ }^{11}$

De acordo com a Organização Mundial de Saúde (OMS), considera-se que o profissional que atende a partos de forma segura deve ser treinado a partir de programas de educação que permitam o desenvolvimento das habilidades necessárias para acompanhamento da gravidez, partos normais e puerpério imediato. ${ }^{12} \mathrm{~A}$ Confederação Internacional de Parteiras Profissionais (ICM) é uma organização não governamental que representa associações de parteiras profissionais em 115 países mundialmente. Essa organização atua com a finalidade de atingir objetivos comuns no cuidado às mulheres e recém-nascidos, entre eles, a qualificação da atenção ao nascimento. No ano de 2019 foi publicado um documento que atualiza a relação de competências essenciais preconizadas mundialmente para a prática da obstetrícia, descrevendo conhecimentos, habilidades e comportamentos profissionais mínimos que devem ser desenvolvidos nos programas de educação para que o indivíduo seja considerado uma parteira profissional certificada, conforme a definição da organização. ${ }^{13-14}$

Considerando o documento intitulado "Essential competencies for midwifery practice - 2019 update" pela ICM, podemos consultar as competências descritas e validadas por especialistas em todo o mundo com a finalidade de servir de base para programas de formação em enfermagem obstétrica, dar instruções claras sobre o exercício da profissão, auxiliar professores com relação às destrezas necessárias a parteira profissional e servir de marco regulatório para auxílio na tomada de decisão por gestores quanto a prática profissional. ${ }^{15}$

É importante considerar que a competência essencial se relaciona ao desempenho desse profissional, mas não são sinônimos. O desempenho profissional se caracteriza pelas ações do sujeito no seu contexto real de prática. Este desempenho é determinado pela capacidade adquirida de acordo com o alcance das competências da profissão. ${ }^{15}$

Dessa forma, as competências essenciais para prática da enfermagem obstétrica são sensíveis aos diferentes cenários que essas profissionais atuam, sendo relevante conhecer a produção científica dos últimos anos a respeito do que é esperado da enfermeira obstetra mundialmente, e a relação desses estudos com diretrizes internacionais para prática da profissão se torna relevante. 0 presente 
estudo tem o objetivo de analisar através de uma revisão integrativa de literatura a produção de conhecimento científico no mundo a respeito das competências essenciais para prática profissional da enfermagem obstétrica.

\section{MATERIAIS E MÉTODOS}

Trata-se de uma revisão integrativa de literatura, conforme proposto por Mendes, Silveira e Galvão, desenvolvida em seis etapas: estabelecimento da questão de pesquisa, busca na literatura, categorização dos estudos encontrados (de acordo com os critérios de inclusão e exclusão estabelecidos), avaliação dos estudos selecionados, interpretação dos resultados e apresentação da revisão. ${ }^{16}$

Os artigos foram buscados nas bases de dados eletrônicas: Literatura LatinoAmericana e do Caribe em Ciências da Saúde (LILACS) e National Library of Medicine National Institutes of Health (PubMed). As palavras-chave utilizadas para execução da busca por estudos foram os Descritores em Ciência da Saúde (DeCS) da Bireme: “competência profissional”, “enfermeira obstétrica” ou "enfermagem obstétrica e os descritores MeSH (Medical Subject Headings) "professional competence" e "midwifery", além de termos relacionados. Foram utilizados os operadores booleanos "and" e "or" para cruzamento dos termos na busca.

Os critérios de inclusão foram artigos originais de pesquisa, revisão ou reflexão, disponíveis integralmente de forma eletrônica, publicados em qualquer idioma, entre os anos de 2011 e 2020 e que respondessem à questão norteadora: quais as competências essenciais para prática da enfermagem obstétrica encontradas na literatura nos últimos 10 anos?

A coleta de dados se deu no mês de julho de 2020, retornou um total de 352 artigos, desses, todos tiveram o título e resumo lidos para avaliar a pertinência com a questão norteadora do estudo. Dos estudos incluídos na revisão, após leitura de título e resumo, 28 artigos foram lidos na íntegra, resultando na amostra final composta de nove artigos que foram incorporados à análise, conforme a Figura 1. 
Figura 1 - Diagrama da aplicação de filtros de pesquisa, limites e critérios de inclusão.

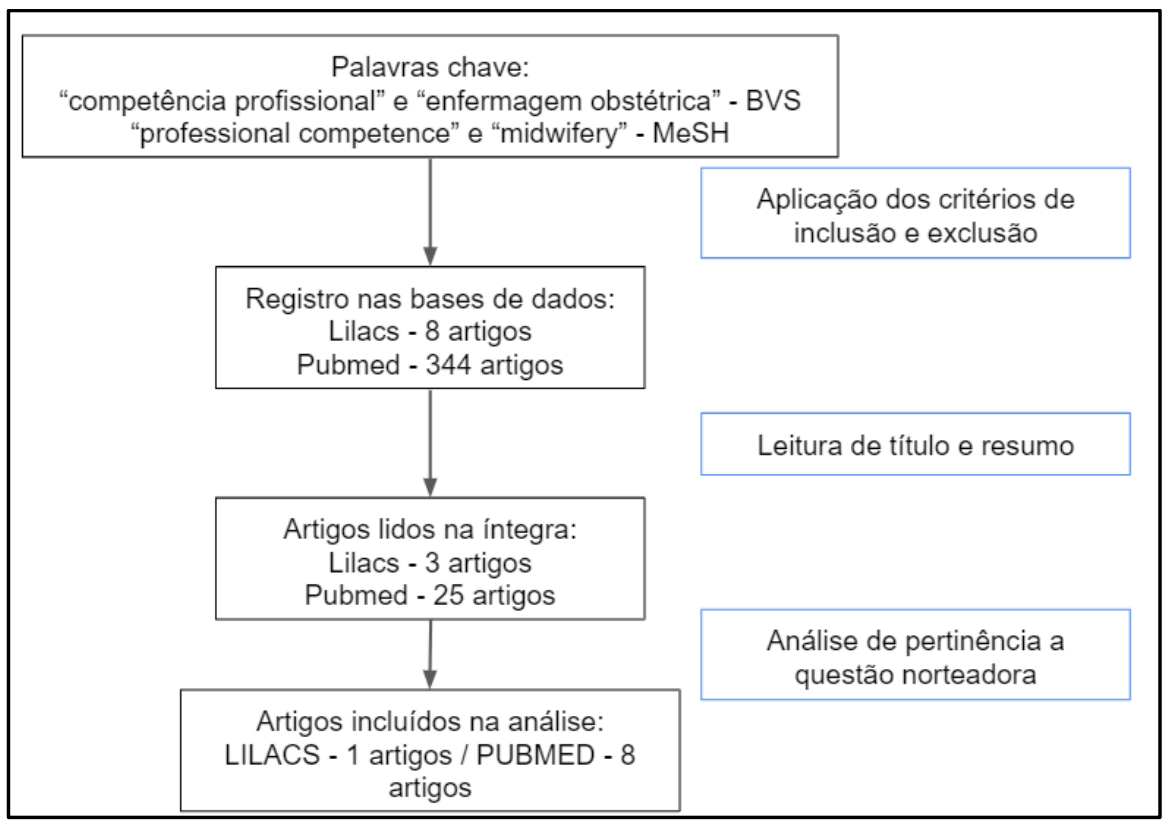

Fonte: Autora, 2020.

Para análise dos artigos incluídos na revisão foi criada uma ficha de extração de dados com as variáveis: título, autoria, periódico e ano de publicação, objetivos, tipo de estudo, amostra/população, local/campo de estudo, coleta de dados, resultados e conclusões. No Quadro 1, as principais informações extraídas dos estudos primários incluídos na revisão foram apresentadas.

Quadro 1 - Síntese dos artigos incluídos na revisão integrativa, 2020.

\begin{tabular}{|c|c|c|c|c|c|}
\hline $\begin{array}{l}\text { Código } \\
\text { do } \\
\text { artigo }\end{array}$ & $\begin{array}{l}\text { Ano/país/ } \\
\text { base de } \\
\text { dados }\end{array}$ & $\begin{array}{l}\text { Autores/ } \\
\text { Tipo de } \\
\text { estudo }\end{array}$ & $\begin{array}{l}\text { Objetivos/ } \\
\text { método }\end{array}$ & $\begin{array}{l}\text { Amostra/ } \\
\text { população }\end{array}$ & Principais resultados \\
\hline $\mathrm{A} 1$ & $\begin{array}{l}2019 \\
\text { Bangladesh } \\
\text { PUBMED }\end{array}$ & $\begin{array}{l}\text { M. Bogren et } \\
\text { al }^{17} \\
\text { Exploratório, } \\
\text { descritivo, } \\
\text { qualitativo }\end{array}$ & $\begin{array}{l}\text { Avaliar a } \\
\text { utilidade } \\
\text { percebida por } \\
\text { instrutores em } \\
\text { obstetrícia de } \\
\text { um curso } \\
\text { baseado em } \\
\text { simulações } \\
\text { para formação } \\
\text { de midwives }\end{array}$ & $\begin{array}{l}17 \\
\text { educadores } \\
\text { em } \\
\text { obstetrícia } \\
\text { de } 15 \\
\text { instituições } \\
\text { em } \\
\text { Bangladesh }\end{array}$ & $\begin{array}{l}\text { O curso proporcionou melhora no } \\
\text { conhecimento teórico e aquisição } \\
\text { de habilidades práticas para } \\
\text { manejo do parto e emergências } \\
\text { obstétricas. } \\
\text { A incorporação de novas } \\
\text { tecnologias no ensino de } \\
\text { obstetrícia, utilizando } \\
\text { metodologias ativas. }\end{array}$ \\
\hline $\mathrm{A} 2$ & $\begin{array}{l}2018 \\
\text { Etiópia } \\
\text { PUBMED }\end{array}$ & $\begin{array}{l}\text { M. Goshu et } \\
\mathrm{al}^{18} \\
\text { Estudo }\end{array}$ & $\begin{array}{l}\text { Avaliar a } \\
\text { competência } \\
\text { de midwives e } \\
\text { fatores }\end{array}$ & $\begin{array}{l}144 \text { midwives } \\
\text { de } 57 \\
\text { instituições } \\
\text { da região de }\end{array}$ & $\begin{array}{l}\text { A competência de midwives na } \\
\text { região de Tigray na Etiópia foi } \\
\text { baixa, sugerindo preocupações } \\
\text { quanto à qualidade da assistência }\end{array}$ \\
\hline
\end{tabular}




\begin{tabular}{|c|c|c|c|c|c|}
\hline & & $\begin{array}{l}\text { transversal, } \\
\text { quantitativo }\end{array}$ & $\begin{array}{l}\text { associados ao } \\
\text { cuidados } \\
\text { prestado } \\
\text { durante parto, } \\
\text { nascimento e } \\
\text { puerpério } \\
\text { imediato }\end{array}$ & $\begin{array}{l}\text { Tigray, } \\
\text { Etiópia }\end{array}$ & $\begin{array}{l}\text { prestada a mulheres e recém- } \\
\text { nascidos na região. }\end{array}$ \\
\hline $\mathrm{A} 3$ & $\begin{array}{l}2018 \\
\text { África do } \\
\text { Sul } \\
\text { PUBMED }\end{array}$ & $\begin{array}{l}\text { KG. } \\
\text { Netshisaulu, } \\
\text { MS Maputle }{ }^{19} \\
\text { Estudo } \\
\text { exploratório, } \\
\text { descritivo, } \\
\text { qualitativo }\end{array}$ & $\begin{array}{l}\text { Explorar as } \\
\text { expectativas } \\
\text { de midwives } \\
\text { experientes } \\
\text { sobre a } \\
\text { competência } \\
\text { clínica de } \\
\text { graduandos em } \\
\text { obstetrícia } \\
\text { durante a } \\
\text { atuação em } \\
\text { serviços } \\
\text { comunitários }\end{array}$ & $\begin{array}{l}25 \text { midwives } \\
\text { com } \\
\text { experiência } \\
\text { de atuação } \\
\text { de pelo } \\
\text { menos } 5 \text { anos } \\
\text { nas } \\
\text { instituições }\end{array}$ & $\begin{array}{l}\text { Pouca demonstração de } \\
\text { independência profissional das } \\
\text { profissionais recém-graduadas. } \\
\text { Participação limitada na divisão } \\
\text { de tarefas: midwives acabam } \\
\text { precisando supervisionar as } \\
\text { colegas. } \\
\text { As profissionais recém-graduadas } \\
\text { pareciam pouco comprometidas. } \\
\text { A falta de competência técnica } \\
\text { foi destacada como fator } \\
\text { prejudicial para qualidade e } \\
\text { eficiência do serviço. }\end{array}$ \\
\hline A4 & $\begin{array}{l}2018 \\
\text { África do } \\
\text { Sul } \\
\text { PUBMED }\end{array}$ & $\begin{array}{l}\text { MR Mpeli20 } \\
\text { Estudo } \\
\text { descritivo, } \\
\text { qualitativo }\end{array}$ & $\begin{array}{l}\text { Descrever a } \\
\text { análise de } \\
\text { narrativas de } \\
\text { auto-avaliação } \\
\text { de estudantes } \\
\text { de obstetrícia } \\
\text { lidando com } \\
\text { dilemas éticos } \\
\text { da vida real }\end{array}$ & $\begin{array}{l}14 \\
\text { estudantes } \\
\text { de } \\
\text { obstetrícia }\end{array}$ & $\begin{array}{l}\text { Apesar dos participantes se } \\
\text { considerarem aptos para lidar } \\
\text { com dilemas éticos em } \\
\text { obstetrícia, a competência ética } \\
\text { propriamente dita foi limitada } \\
\text { nas narrativas. } \\
\text { O estudo recomenda que as } \\
\text { instituições de formação em } \\
\text { enfermagem devem incluir } \\
\text { discussões na formação de } \\
\text { profissionais a respeito de teorias } \\
\text { morais. }\end{array}$ \\
\hline A5 & $\begin{array}{l}2017 \\
\text { Etiópia } \\
\text { PUBMED }\end{array}$ & $\begin{array}{l}\text { Kibwana et } \\
\text { al }^{21} \\
\text { Estudo } \\
\text { descritivo, } \\
\text { qualitativo }\end{array}$ & $\begin{array}{l}\text { Explorar a } \\
\text { percepção de } \\
\text { instrutores a } \\
\text { respeito da } \\
\text { adequação da } \\
\text { experiência de } \\
\text { aprendizado } \\
\text { dos estudantes } \\
\text { e a implicação } \\
\text { para alcance } \\
\text { de maestria } \\
\text { em } \\
\text { competências } \\
\text { essenciais em } \\
\text { obstetrícia }\end{array}$ & $\begin{array}{l}\text { Um instrutor, } \\
\text { um assistente } \\
\text { de } \\
\text { laboratório e } \\
\text { um preceptor } \\
\text { de cada um } \\
\text { dos } 32 \\
\text { programas de } \\
\text { formação de } \\
\text { parteiras e } \\
\text { anestesistas } \\
\text { na Etiópia }\end{array}$ & $\begin{array}{l}\text { Deficiências do ambiente de } \\
\text { aprendizado limitam o } \\
\text { desenvolvimento de } \\
\text { competências centrais para a } \\
\text { prática da parteria. } \\
\text { Sugere-se critérios de admissão } \\
\text { aos programas mais rígidos, } \\
\text { adaptação dos currículos a } \\
\text { normas internacionais para } \\
\text { avaliação de competências } \\
\text { profissionais, adaptação do } \\
\text { currículo à realidade dos } \\
\text { serviços. } \\
\text { Aumento do uso de simulação } \\
\text { para assistência ao parto. }\end{array}$ \\
\hline A6 & $\begin{array}{l}2016 \\
\text { Gana } \\
\text { PUBMED }\end{array}$ & $\begin{array}{l}\text { Lohela et al } 22 \\
\text { Estudo } \\
\text { transversal, } \\
\text { quantitativo }\end{array}$ & $\begin{array}{l}\text { Avaliar a } \\
\text { competência } \\
\text { de profissionais } \\
\text { de saúde no } \\
\text { atendimento } \\
\text { de } \\
\text { emergências } \\
\text { obstétricas, }\end{array}$ & $\begin{array}{l}\text { Três } \\
\text { médicos, } 38 \\
\text { midwives, } \\
\text { cinco } \\
\text { médicos- } \\
\text { assistentes, } \\
\text { nove } \\
\text { enfermeiras }\end{array}$ & $\begin{array}{l}\text { Sugere que outros profissionais, } \\
\text { que não sejam médicos ou } \\
\text { midwives, parecem não prover } \\
\text { cuidado competente e de } \\
\text { qualidade para manejo de } \\
\text { emergências obstétricas. } \\
\text { O volume de atendimentos e }\end{array}$ \\
\hline
\end{tabular}




\begin{tabular}{|c|c|c|c|c|c|}
\hline & & & $\begin{array}{l}\text { utilizando } \\
\text { estudos de } \\
\text { caso. }\end{array}$ & $\begin{array}{l}\text { e nove } \\
\text { profissionais } \\
\text { com } \\
\text { formação } \\
\text { diferenciada } \\
\text { (profissionais } \\
\text { de saúde não } \\
\text { médicos, } \\
\text { parteiras } \\
\text { tradicionais e } \\
\text { profissionais } \\
\text { de nível } \\
\text { técnico) }\end{array}$ & $\begin{array}{l}\text { maior carga de trabalho em } \\
\text { atenção ao parto se relacionou a } \\
\text { maior experiência e maior } \\
\text { capacidade de atenção adequada } \\
\text { às emergências obstétricas. }\end{array}$ \\
\hline A7 & $\begin{array}{l}2015 \\
\text { Etiópia } \\
\text { PUBMED }\end{array}$ & $\begin{array}{l}\text { Yigzaw et } \\
\text { al }^{23} \\
\text { Estudo } \\
\text { transversal, } \\
\text { quantitativo }\end{array}$ & $\begin{array}{l}\text { Gerar } \\
\text { evidência } \\
\text { sobre a } \\
\text { qualidade da } \\
\text { educação em } \\
\text { obstetrícia, } \\
\text { avaliando a } \\
\text { competência } \\
\text { dos estudantes } \\
\text { de parteria no } \\
\text { momento da } \\
\text { graduação. }\end{array}$ & $\begin{array}{l}484 \\
\text { estudantes } \\
\text { de graduação } \\
\text { em } \\
\text { enfermagem } \\
\text { obstétrica } \\
\text { em } 25 \\
\text { instituições } \\
\text { públicas da } \\
\text { Etiópia }\end{array}$ & $\begin{array}{l}\text { A performance média dos } \\
\text { participantes foi insatisfatória e a } \\
\text { maioria dos estudantes de } \\
\text { instituições públicas não } \\
\text { dominavam as competências } \\
\text { essenciais para prática segura e } \\
\text { efetiva da obstetrícia. } \\
\text { O desempenho para atendimento } \\
\text { de emergências obstétricas com } \\
\text { vácuo extrator foram os mais } \\
\text { baixos. } \\
\text { O ambiente de aprendizado } \\
\text { prático foi deficiente. }\end{array}$ \\
\hline A8 & $\begin{array}{l}2014 \\
\text { Índia } \\
\text { PUBMED }\end{array}$ & $\begin{array}{l}\text { S Chaturvedi } \\
\text { et al } 24 \\
\text { Estudo } \\
\text { transversal, } \\
\text { quantitativo }\end{array}$ & $\begin{array}{l}\text { Avaliar, } \\
\text { utilizando } \\
\text { estudos de } \\
\text { caso, se os } \\
\text { profissionais } \\
\text { atendendo } \\
\text { partos são } \\
\text { competentes } \\
\text { na prestação } \\
\text { de cuidados a } \\
\text { emergências } \\
\text { obstétricas. }\end{array}$ & $\begin{array}{l}233 \\
\text { enfermeiras } \\
\text { que atendem } \\
\text { a partos em } \\
73 \\
\text { instituições } \\
\text { vinculadas ao } \\
\text { programa } \\
\text { Janani } \\
\text { Surasksha } \\
\text { Yojana (JSY) }\end{array}$ & $\begin{array}{l}\text { Os participantes com treinamento } \\
\text { específico para atenção ao parto, } \\
\text { apesar de pontuações baixas, } \\
\text { tiveram melhor desempenho do } \\
\text { que profissionais generalistas. Os } \\
\text { profissionais atuantes em } \\
\text { instituições de maior } \\
\text { complexidade também } \\
\text { pontuaram melhor, e aqueles que } \\
\text { atuavam em instituições com } \\
\text { volume de partos maior do que } \\
30 \text { partos por mês. }\end{array}$ \\
\hline A9 & $\begin{array}{l}2012 \\
\text { Brasil } \\
\text { LILACS }\end{array}$ & $\begin{array}{l}\text { PW Parenti } \\
\text { et al } 25 \\
\text { Estudo } \\
\text { descritivo, } \\
\text { qualitativo }\end{array}$ & $\begin{array}{l}\text { Identificar as } \\
\text { competências } \\
\text { que as } \\
\text { enfermeiras } \\
\text { mobilizam na } \\
\text { assistência } \\
\text { pré-natal das } \\
\text { adolescentes. }\end{array}$ & $\begin{array}{l}\text { Dez } \\
\text { enfermeiras } \\
\text { que prestam } \\
\text { assistência } \\
\text { pré-natal há } \\
\text { pelo menos } \\
\text { um ano, com } \\
\text { faixa-etária } \\
\text { entre } 23 \text { e } 26 \\
\text { anos de } \\
\text { idade }\end{array}$ & $\begin{array}{l}\text { Para as enfermeiras trabalharem } \\
\text { na perspectiva da competência } \\
\text { dialógica, articulando } \\
\text { habilidades, conhecimento, e } \\
\text { atitudes, a percepção do } \\
\text { entendimento do contexto de } \\
\text { vida, a utilização de linguagem } \\
\text { adequada e a comunicação } \\
\text { interpessoal efetiva devem ser } \\
\text { incorporados em suas ações. } \\
\text { A construção de protocolos } \\
\text { assistenciais, deve ser assumida } \\
\text { pelas enfermeiras, adotando o } \\
\text { referencial das competências } \\
\text { como norteador da mudança do } \\
\text { modelo assistencial. }\end{array}$ \\
\hline
\end{tabular}

Fonte: Autora, 2020. 


\section{RESULTADOS}

Dos nove artigos incluídos na análise, a maioria das produções eram procedentes de países do continente africano $(66,6 \%)$, seguido de artigos de países asiáticos (22,2\%) e um artigo brasileiro, produzido na América do Sul $(11,1 \%)$. Quanto ao ano de publicação, os estudos incluídos na revisão foram publicados entre os anos de 2012 e 2019, com destaque ao ano de 2018 que concentrou três dos artigos incluídos na amostra. Quanto ao idioma de publicação, oito artigos foram publicados em língua inglesa $(88,8 \%)$ e um em português. O único artigo publicado em português na busca realizada evidencia a escassez de produção científica brasileira acerca do tema nos últimos 10 anos. Quanto à abordagem dos estudos, cinco deles $(55,5 \%)$ tinham abordagem qualitativa e quatro eram estudos quantitativos, do tipo estudo transversal.

\section{DISCUSSÃO}

Dos estudos incluídos na revisão, cabe destacar a procedência dos artigos, na sua grande maioria, desenvolvidos em países de baixa e média renda (A1-A8). A produção científica emergente nesses países, nos últimos 20 anos, parece se justificar pela expansão dos sistemas de saúde locais, pela criação de programas para promoção de saúde da mulher e do recém-nascido, bem como da necessidade de avaliação dos programas desenvolvidos nesses países com o objetivo de reduzir a mortalidade materna e neonatal. ${ }^{26}$

Quanto aos profissionais incluídos nos estudos, vale a discussão acerca de quem são os profissionais capacitados mundialmente para a assistência ao parto. Uma scoping review publicada em 2019, que objetivou identificar e mapear os profissionais considerados aptos a assistir partos em países de baixa e média renda, evidenciou que existem mais de 100 profissionais com diferentes formações e titulações que atuam no cenário do parto mundialmente. Desses, 16\% eram médicos, $16 \%$ eram enfermeiras generalistas e $16 \%$ eram midwives, representando um grupo heterogêneo entre os países investigados, e até mesmo, dentro de um mesmo país. ${ }^{27}$ Dos estudos incluídos na análise deste artigo, um deles concluiu que outros profissionais, que não sejam médicos ou midwives, parecem não prover cuidado competente e de qualidade para manejo de emergências obstétricas (A6). 
No ano de 2018, a OMS, a ICM e outras organizações internacionais médicas e de enfermagem declararam que o profissional apto a assistência ao parto deve ser, prioritariamente, uma parteira profissional, enfermeira ou médico que tenha recebido educação formal e treinado para desempenhar as habilidades necessárias à assistência ao nascimento, à mulher e ao recém-nascido, de gestações nãocomplicadas e que sejam capazes de referenciar a serviços de maior complexidade no caso de intercorrências obstétricas. ${ }^{28} \mathrm{~A}$ fim de minimizar as diferenças na formação desses profissionais, a declaração conjunta da OMS e ICM ainda destaca que o foco de avaliação da formação deve ser o desempenho em competências essenciais para prática da obstetrícia, além do reconhecimento de medidas básicas de atenção a emergências obstétricas. ${ }^{27}$

Em três dos estudos quantitativos incluídos nesta revisão, a competência técnica dos profissionais que assistiam aos partos foi considerada insuficiente ( $A 2$, A7 e A8). Os profissionais que assistiam aos partos tiveram baixa competência no manejo de emergências obstétricas, pouca habilidade para avaliação rápida da paciente no primeiro contato e pouco domínio do uso de partograma e monitorização do progresso do trabalho de parto (A2 e A8). A identificação, manejo e tomada de decisão apropriados na identificação de emergências obstétricas no momento do parto é peça chave para o sucesso do cuidado à parturiente, diminuindo índices de mortalidade materna. ${ }^{29}$ A mortalidade materna em países de baixa e média renda, especialmente, em países da África Subsaariana e Ásia são responsáveis por mais da metade de todas as mortes relacionadas a afecções perinatais no mundo. ${ }^{30}$ As maiores complicações obstétricas relacionadas a morte materna são: hemorragias, infecções, distúrbios hipertensivos e o aborto inseguro. ${ }^{30}$

Um dos estudos destacou o baixo desempenho de parteiras profissionais para atendimento de emergências obstétricas com vácuo extrator e no manejo de aborto por aspiração manual intrauterina (A7). Pelo menos duas revisões sistemáticas conduzidas na última década concluem que não há diferença significativa nos desfechos de situações de aborto em primeiro trimestre manejados por profissionais médicos, ou não-médicos, como parterias profissionais capacitadas para isso. ${ }^{31-32}$ Considerando esses estudos, bem como a opinião de especialistas em enfermagem obstétrica, a competência da enfermeira obstétrica no manejo de aborto foi reafirmada em estudo publicado em $2018 .{ }^{33}$ Esta publicação impulsionou a inclusão 
de competências relacionadas ao manejo de abortamento por midwives nas competências da profissão na atualização do documento da ICM publicado em outubro de 2019. ${ }^{14}$ No Brasil, a lei que regulamenta a atuação de enfermeiras obstetras não prevê atuação direta e tomada de conduta a fim realizar esvaziamento uterino seguro em situações de abortamento, mas a ausência de respaldo legal para atuação nesse contexto não exclui a importância de inclusão dos profissionais da enfermagem no manejo multidisciplinar de situação de perdas gestacionais. ${ }^{34}$

A formação de parteiras profissionais nos estudos incluídos na revisão parece sofrer influência significativa do ambiente de aprendizado onde as práticas ocorrem (A3, A5 e A7). Dentre as dificuldades encontradas destaca-se a falta de estrutura para formação dos profissionais, ausência de ambientes para simulações de práticas em obstetrícia e dificuldades para garantir que os alunos participassem de situações reais como reanimação neonatal e atenção ao parto, propriamente dito (A3, A5 e A7). A limitação das experiências na formação em obstetrícia causou uma avaliação negativa dos estudantes em um dos estudos, considerando o cenário de aprendizado limitado, prejudicando o desenvolvimento das habilidades profissionais (A7).

Achados semelhantes em uma pesquisa que avaliou as expectativas de enfermeiras quanto a especialização em enfermagem obstétrica na modalidade de residência no Brasil evidenciam a percepção de que há uma dissociação entre teoria e prática na formação profissional. ${ }^{35} \mathrm{O}$ estudo brasileiro destaca o descontentamento dos profissionais em formação com as oportunidades limitadas que encontram nos hospitais brasileiros para desenvolver habilidades técnicas, inclusive com restrição de atendimento a partos por enfermeiras nas instituições. ${ }^{35} \mathrm{Um}$ dos estudos da revisão destaca em seus resultados como o número de partos atendidos pelos profissionais em formação, bem como o volume de trabalho na instituição avaliada, se relaciona a melhor desempenho na avaliação de competências profissionais (A6).

Ainda sobre o processo de formação de enfermeiras obstetras, um dos estudos destaca a importância do desenvolvimento da competência profissional como instrutores em obstetrícia de professores e preceptores dos cursos de formação (A1). O aprimoramento contínuo serve como subsídio para adquirir e compartilhar conhecimentos que vão aprimorar a prática e ensino da obstetrícia (A1). Considerando o cenário brasileiro e o recente Projeto de Aprimoramento e Inovação no Cuidado e Ensino em Obstetrícia e Neonatologia (Apice ON), salienta-se a 
experiência dos profissionais que participaram de cursos de atualização para o cuidado e gestão, com foco no parto e no nascimento. ${ }^{36} \mathrm{Em}$ um relato de experiência de profissionais participantes do projeto, foi demonstrada a importância de qualificação técnica de profissionais já formadas, fato que contribuiu para mudança do modelo de atenção ao parto, menos medicalizado e mais voltado à autonomia da mulher. As ações de educação continuada realizadas no cenário prático de assistência ao parto reforçaram a identificação profissional de enfermeiras obstetras, na medida que permitiu a atualização de técnicas e práticas relacionadas à atenção ao parto ${ }^{36}$ e puderam servir de subsídio para pensar mudanças nos cenários onde atuam.

Ainda sobre os resultados encontrados nos estudos incluídos na análise desta revisão, cabe o comentário sobre questões de gênero relacionadas ao desempenho profissional de enfermeiros obstetras. Resultados de escores relacionados às competências para assistência ao parto foram maiores para participantes homens em pelo menos dois dos estudos citados (A2 e A7). Os resultados mostraram que ser homem esteve associado a maiores escores em competências específicas, incluindo avaliação rápida da paciente em triagem, coleta de dados do histórico de saúde e obstétrico, exame físico, uso de partograma, assistência ao parto, cuidados imediatos no pós-parto, julgamento clínico e tomada de decisão (A2). Apesar de alguns estudos na literatura não terem evidenciado influência de gênero no desempenho acadêmico de cursos de formação profissional para saúde, ${ }^{37}$ ambos estudos incluídos na revisão evidenciaram diferença significativa de desempenho masculino relacionados às competências da parteira profissional. Ambos estudos foram desenvolvidos na Etiópia, país onde há grande disparidade entre as oportunidades de educação para homens e mulheres (A2 e A7), o que justifica pontos de corte para acesso aos cursos de formação menores para mulheres, fato que, aparentemente, dificulta a permanência nos cursos com desempenho satisfatório. Um estudo que avaliou fatores que influenciam a atuação de homens na enfermagem em países em desenvolvimento foi encontrada relação do trabalho do enfermeiro do sexo masculino com maior rapidez no avanço na carreira e alcance de posições de chefia em tempo menor do que colegas mulheres que se assemelhavam no conhecimento técnico da profissão. ${ }^{38}$ Paradoxalmente, quando se considera o recorte histórico da enfermagem mundial, a profissão historicamente feminina reserva ainda 
atualmente dificuldades de inserção de homens num ambiente majoritariamente ocupado por mulheres. ${ }^{39}$

Finalmente, dos resultados encontrados nos estudos na análise, cabem as competências relacionais da atuação como enfermeiras obstetras, que fogem aos requisitos técnicos para prática da profissão, mas compõem a forma que as relações de trabalho e de cuidado se dão. 0 destaque do estudo incluído é para competência dialógica da profissional (A9), exigindo das profissionais adequação da linguagem utilizada para que o cuidado se torne relevante as diferentes mulheres atendidas, com foco na comunicação interpessoal efetiva e culturalmente sensível para melhora dos desfechos assistenciais, conforme preconizado pela ICM. ${ }^{14}$

Já considerando aspectos éticos da atuação da enfermeira obstetra, um dos estudos destaca a necessidade de desenvolvimento de competência ética para atuação nas equipes e, principalmente, com usuárias dos sistemas de saúde (A4). 0 estudo destaca a importância de que profissionais reflitam a respeito do código de ética e princípios profissionais quando justificam ações na assistência ao parto, fortalecendo a autonomia da profissão (A4). A literatura destaca como principais entraves ao desenvolvimento pleno de autonomia do enfermeiro obstetra fatores como: déficits na formação, resistência do profissional médico à atuação, incerteza quanto à prática profissional e desconhecimento da legislação que respalda a prática profissional. ${ }^{40} \mathrm{~A}$ atuação do enfermeiro de forma autônoma é potencial agente propulsor de cuidado humanizado no cenário do nascimento, ${ }^{41}$ mas necessita de suporte de gestores para que o incentivo e valorização do seu trabalho se reflita em apoio institucional para atuação da enfermagem obstétrica de forma autônoma. ${ }^{42}$

\section{CONCLUSÃO}

Permitir que profissionais sem competência essencial adequada atuem em seus campos de prática aumenta riscos para segurança do paciente, influencia de forma negativa na confiança pública na profissão e nos sistemas de saúde mundialmente e ainda prejudica indicadores de qualidade na assistência materna e neonatal. ${ }^{23}$ Esses fatores justificam a necessidade de fortalecimento de programas de formação profissional, atualização de instrutores em obstetrícia e articulação de programas teóricos com oportunidades práticas em obstetrícia que proporcionem o 
desenvolvimento de habilidades para a atuação autônoma como enfermeiras obstetras.

O estabelecimento da legitimidade da atenção de enfermeiras obstetras ao parto de risco habitual como competência essencial do profissional brasileiro ainda se configura como um desafio para a assistência obstétrica no país. Parte desse desafio é consequência da falta de autonomia de gestores nos serviços, que por vezes impossibilita a inserção da enfermeira obstétrica no parto e nascimento devido a obstáculos como questões financeiras, administrativas, escassez de recursos humano e relações de poder entre equipes médica e de enfermagem desiguais. ${ }^{43}$ Soma-se a isso a falta de autonomia dos próprios profissionais quanto ao exercício profissional de que são capazes.

Considerando os achados na revisão e o atual cenário de atuação de enfermeiras obstétricas no Brasil, cabe a possibilidade de ampliação futura da atuação dessas profissionais, seguindo o exemplo de países onde a atuação abrange o manejo em situações de abortamento e realização de ultrassonografias, por exemplo.

Exemplo de atuação ampliada de enfermeiros obstetras no seu escopo de prática no Brasil é a inserção de DIU de cobre, método contraceptivo de longa permanência que teve a oferta ampliada no SUS e afirmada pelo Conselho Federal de Enfermagem no ano de 2010 como legítima ao enfermeiro. ${ }^{44}$ Essa prática, consolidada em alguns serviços pelo país, está em constante discussão acerca da legalidade, apesar de experiências positivas bem descritas na literatura, com altas taxas de satisfação das usuárias com o método, taxas de complicações semelhantes aos dispositivos introduzidos por profissionais médicos e pela contribuição para ampliação de oferta de métodos de planejamento reprodutivo disponíveis nos serviços públicos de saúde. ${ }^{45}$ Além de ações pontuais como a inserção do DIU de cobre pós-placentário e em ambiente ambulatorial.

Dentre as limitações deste estudo podemos considerar as características metodológicas dos estudos incluídos na análise: estudos observacionais, na maioria de recorte transversal ou qualitativos. Estes desenhos de pesquisas não permitem a generalização dos resultados, apenas a geração de hipóteses a partir dos dados encontrados. Outra fragilidade do estudo é a variedade de categorias profissionais envolvidas na assistência ao parto que compuseram as amostras nos estudos 
analisados, marcando a heterogeneidade dos profissionais envolvidos na assistência, bem como do processo de formação e avaliação dos mesmos.

A relevância desta revisão consiste na síntese de estudos produzidos nos últimos anos que avaliam a competência profissional de enfermeiras obstétricas e permite a reflexão acerca de programas vigentes de formação desses profissionais no país e no mundo. Os achados dos estudos e a discussão com a produção científica a respeito desses resultados permitem o levantamento de hipóteses sobre potencialidades e fragilidades do modo de formar profissionais para atenção ao parto no Brasil, cabendo ainda a possibilidade de estudos futuros que avaliem a situação atual de cursos de formação em enfermagem obstétrica, a forma de avaliação de competência profissional utilizada nos diferentes cenários e quais as implicações para assistência em cenário real da qualidade de formação desses profissionais.

\section{REFERÊNCIAS}

1 - Sena CD, Santos TCS, Carvalho CMF, Sá ACM, Paixão GPN. Avanços e retrocessos da enfermagem obstétrica no Brasil. Revista de Enfermagem da UFSM [Online], 2.3 (2012): 523-529.27 Nov. 2020. Disponível em:

https: / / periodicos.ufsm.br/reufsm/article/view/3365.

2 - Brasil. Ministério da Saúde. Humanização do parto e do nascimento / Ministério da Saúde. Universidade Estadual do Ceará. - Brasília, 2014. 465 p.: il. - (Cadernos HumanizaSUS; v.4). Disponível em:

https://www.redehumanizasus.net/sites/default/files/caderno_humanizasus_v4_h umanizacao_parto.pdf

3 - Fertonani HP, Pires DEP, Biff D, Scherer MDA. Modelo assistencial em saúde: conceitos e desafios para a atenção básica brasileira. Ciênc. saúde coletiva [Internet]. 2015 Jun. [cited 2020 Dec 28]; 20(6): 1869-1878. Disponível em: http://www.scielo.br/scielo.php?script=sci_arttext\&pid=S1413$81232015000601869 \& \operatorname{lng}=\mathrm{en}$

4 - Narchi NZ. Análise do exercício de competências dos médicos não médicos para 
atenção à maternidade. Saude soc. [Internet]. Março de 2010 [citado em 28 de dezembro de 2020]; 19 (1): 147-158. Disponível em:

http: / / www.scielo.br/scielo.php?script=sci_arttext\&pid=S0104$\underline{12902010000100012 \& \operatorname{lng}=e n}$

5 - Riesco MLG, Fonseca RMGS. Elementos constitutivos da formação e inserção de profissionais não-médicos na assistência ao parto. Cad. Saúde Pública [Internet]. 2002 June [cited 2020 Nov 13]; 18(3): 685-698. Disponível em:

https: //www.scielo.br/scielo.php?pid=S0102311X2002000300012\&script=sci_abstract\&tlng=pt

6 - Amorim T, Gualda DMR. Coadjuvantes das mudanças no contexto do ensino e da prática da enfermagem obstétrica. Revista Rene. 2011, out/dez; 12(4):833-40. Disponível em: http://www.periodicos.ufc.br/rene/article/view/4352

7 - Cintra NR, Riesco MLG. Caracterização dos cursos de graduação em Obstetrícia em países da América do Sul. Interface (Botucatu) [Internet]. 2019 [cited 2020 Nov 12] ; 23: e180505. Disponível em:

http://www.scielo.br/scielo.php?script=sci_arttext\&pid=S1414-32832019000100279

8 - Associação Brasileira de Obstetrizes e Enfermeiros Obstetras - ABENFO.

Competências essenciais para o exercício básico da obstetrícia/2002/ICM (traduzido para o português). Disponível em:

https://www.abenfo.org.br/site/biblioteca/arquivos/manuais/116.pdf

9 - Brasil. Presidência da República. Casa Civil. Subchefia de assuntos jurídicos. Lei $n^{\circ} 7.498$, de 25 de Junho de 1986. Brasília, 1986. Disponível em:

http://www.planalto.gov.br/ccivil_03/Leis/L7498.htm

10 - Caus ECM, Santos EKA, Nassif AA, Monticelli M. O processo de parir assistido pela enfermeira obstétrica no contexto hospitalar: significados para as parturientes. Esc. Anna Nery [Internet]. 2012 Mar [cited 2020 Nov 12]; 16(1): 3440. Disponível em: http://www.scielo.br/scielo.php?script=sci_arttext\&pid=S1414- 


\section{$\underline{81452012000100005}$}

11 - Kak, N, Burkhalter B, Cooper M. Measuring the competence of healthcare providers. Operations Research Issue Paper 2. Bethesda, MD: Published for the U.S. Agency for International Development (USAID) by the Quality Assurance (QA) Project. Jul, 2001. Volume 2, Issue 1. Disponível em: https://www.urcchs.com/sites/default/files/MeasuringCompetenceofHealthcareProviders_July2001. pdf

12 - World Health Organization. Making pregnancy safer: the critical role of the skilled attendant A joint statement by WHO, ICM and FIGO. World Health Organization. 2004. Disponível em:

https://www.who.int/maternal_child_adolescent/documents/9241591692/en/

13 - International Confederation of Midwives - ICM. Annual Report 2018. The Hague, 2018. Disponível em:

https: //www.internationalmidwives.org/assets/files/generalfiles/2019/07/icm_annualreport2018_eng_download.pdf

14 - International Confederation of Midwives - ICM. Essential Competencies for Midwifery Practice - 2019 update. ICM, 2019. Disponível em:

https://www.internationalmidwives.org/assets/files/general-files/2019/10/icmcompetencies-en-print-october-2019_final_18-oct-5db05248843e8.pdf

15 - Organização Panamericana da Saúde. Centro latino-americano de Perinatologia. Conjunto de ferramentas para o fortalecimento da obstetrícia: desafios e contribuições para a formação em obstetrícia no Brasil, 2013. Disponível em: https: / / www.paho.org/clap/index.php?option=com_docman\&view=download\&alias =434-conjunto-de-ferramentas-para-o-fortalecimento-da-parteria-nas-americas3\&category_slug=salud-de-mujer-reproductiva-materna-yperinatal\&ltemid=219\&lang=es 
16 - Mendes KDS, Silveira, RCCP, Galvão CM. Revisão integrativa: método de pesquisa para a incorporação de evidências na saúde e na enfermagem. Texto Contexto Enferm. 2008;17(4):758-64. Disponível em:

http: / / www.scielo.br/scielo.php?script=sci_arttext\&pid=S0104-07072008000400018

17 - Bogren M, Rosengren J, Erlandsson K, Berg M. Build professional competence and Equip with strategies to empower midwifery students - An interview study evaluating a Simulation-based learning course for midwifery educators in Bangladesh. Nurse Educ Pract ; 35: 27-31, 2019 Feb. Disponível em: https://www.sciencedirect.com/science/article/pii/S1471595318306346

18 - Goshu M, Godefay H, Bihonegn F, Ayalew F, Haileselassie D, Kebede A, Temam G, Gidey G. Assessing the competence of midwives to provide care during labor, childbirth and the immediate postpartum period - A cross sectional study in Tigray region, Ethiopia. PLoS One. 2018 Oct 31;13(10):e0206414. Disponível em: https: / / journals.plos.org/plosone/article?id=10.1371/journal.pone.0206414

19 - Netshisaulu KG, Maputle MS. Expected clinical competence from midwifery graduates during community service placement in Limpopo province, South Africa. Health SA. 2018 Nov 29;23:1166. Disponível em:

https: //www.ncbi.nlm.nih.gov/pmc/articles/PMC6917449/

20 - Mpeli MR. Analysis of self-evaluated ethical competence of midwifery students at a selected nursing college in the Free State. Curationis. 2018 Aug 29;41(1):e1e9. Disponível em: https://pubmed.ncbi.nlm.nih.gov/30198296/

21 - Kibwana S, Haws R, Kols A, Ayalew F, Kim YM, van Roosmalen J, Stekelenburg J. Trainers' perception of the learning environment and student competency: A qualitative investigation of midwifery and anesthesia training programs in Ethiopia. Nurse Educ Today. 2017 Aug;55:5-10. Disponível em:

https: //pubmed.ncbi.nlm.nih.gov/28505523/

22 - Lohela TJ, Nesbitt RC, Manu A, Vesel L, Okyere E, Kirkwood B, Gabrysch S. 
Competence of health workers in emergency obstetric care: an assessment using clinical vignettes in Brong Ahafo region, Ghana. BMJ Open. 2016 Jun 13;6(6):e010963. Disponível em: https://bmjopen.bmj.com/content/6/6/e010963

23 - Yigzaw, T, Ayalew, F, Kim, YM. et al. How well does pre-service education prepare midwives for practice: competence assessment of midwifery students at the point of graduation in Ethiopia. BMC Med Educ 15, 130 (2015). Disponível em: https: / / bmcmededuc.biomedcentral.com/articles/10.1186/s12909-015-0410-6

24 - Chaturvedi, S., Upadhyay, S. \& De Costa, A. Competence of birth attendants at providing emergency obstetric care under India's JSY conditional cash transfer program for institutional delivery: an assessment using case vignettes in Madhya Pradesh province. BMC Pregnancy Childbirth 14, 174 (2014). Disponível em: https: / / bmcpregnancychildbirth. biomedcentral.com/articles/10.1186/1471-2393$\underline{14-174}$

25 - Parenti PW, Silva LCFP da, Melo CRME, Clapis MJ. Cuidado pré-natal às adolescentes: competências das enfermeiras [Internet]. Revista Baiana de Enfermagem. 2012 ; 26( 2): 498-509. Disponível em:

https: //periodicos.ufba.br/index.php/enfermagem/article/view/6534

26 - Chersich MF, Martin G. Priority gaps and promising areas in maternal health research in low- and middle-income countries: summary findings of a mapping of 2292 publications between 2000 and 2012. Global Health. 2017 Feb 2;13(1):6. Disponível em: https://pubmed.ncbi.nlm.nih.gov/28153038/

27 - Hobbs AJ, Moller AB, Kachikis A, Carvajal-Aguirre L, Say L, Chou D. Scoping review to identify and map the health personnel considered skilled birth attendants in low-and-middle income countries from 2000-2015. PLoS One. 2019 Feb 1;14(2):e0211576. Disponível em: https://pubmed.ncbi.nlm.nih.gov/30707736/

28 - World Health Organization. Definition of skilled health personnel providing care during childbirth: the 2018 joint statement by WHO, UNFPA, UNICEF, ICM, ICN, 
FIGO and IPA. World Health Organization. 2018. Disponível em:

https: / / www.who.int/reproductivehealth/publications/statement-competent-mnhprofessionals/en/

29 - Campbell O, Graham W. Strategies for reducing maternal mortality: getting on with what works. 2006. Lancet. 368. 1284-99. 10.1016/S0140-6736(06)69381-1. Disponível em: https://www.thelancet.com/journals/lancet/article/PIIS0140$\underline{6736(06) 69381-1 / \text { fulltext }}$

30 - World Health Organization. Maternal mortality - Fact sheet - 2014: To improve maternal health, barriers that limit access to quality maternal health services must be identified and addressed at all levels of the health system. Disponivel em: http://apps.who.int/iris/bitstream/10665/112318/1/WHO_RHR_14.06_eng.pdf?ua= 1

31 - Barnard S, Kim C, Park MH, Ngo TD. Doctors or mid-level providers for abortion. Cochrane Database Syst Rev. 2015 Jul 27;(7):CD011242. Disponível em: https: / / www.cochranelibrary.com/cdsr/doi/10.1002/14651858.CD011242.pub2/ful $\underline{1}$

32 - Renner RM, Brahmi D, Kapp N. Who can provide effective and safe termination of pregnancy care? A systematic review*. BJOG. 2013 Jan;120(1):23-31. Disponível em: https: //pubmed.ncbi.nlm.nih.gov/22900974/

33 - Fullerton J, Butler MM, Aman C, Reid T, Dowler M. Abortion-related care and the role of the midwife: a global perspective. Int J Womens Health. 2018 Nov 23;10:751-762. Disponível em:

https: //www.ncbi.nlm.nih.gov/pmc/articles/PMC6260173/

34 - Domingos SRF, Merighi MAB. O aborto como causa de mortalidade materna: um pensar para o cuidado de enfermagem. Esc. Anna Nery [Internet]. 2010 Mar [cited 2020 Nov 24] ; 14(1): 177-181. Disponível em:

http://www.scielo.br/scielo.php?script=sci_arttext\&pid=S1414- 


\section{$\underline{81452010000100026 \& \operatorname{lng}=e n}$}

35 - Lima GPV, Pereira ALF, Guida NFB, Progianti JM, Araújo CLF, Moura MAV. Expectativas, motivações e percepções das enfermeiras sobre a especialização em enfermagem obstétrica na modalidade residência. Esc. Anna Nery [Internet]. 2015 Dec [cited 2020 Nov 25]; 19(4): 593-599. Disponível em: https: //www.scielo.br/pdf/ean/v19n4/1414-8145-ean-19-04-0593.pdf

36 - Sanfelice CFO, Tiburcio CA, Anastácio JV, Barros GM. Curso de aprimoramento para enfermeiras obstétricas do Projeto Apice On: relato de experiência. Esc. Anna Nery [Internet]. 2020 [cited 2020 Nov 26]; 24(2): e20190212. Disponível em: http: / / www.scielo.br/scielo.php?script=sci_arttext\&pid=S1414$\underline{81452020000200601 \& \operatorname{lng}=e n}$

37 - Johnson P, Fogarty L., Fullerton J. et al. An integrative review and evidencebased conceptual model of the essential components of pre-service education. Hum Resour Health 11, 42 (2013). Disponível em:

https: //pubmed.ncbi.nlm.nih.gov/23984867/

38 - Zamanzadeh V, Valizadeh L, Negarandeh R, Monadi M, Azadi A. Factors influencing men entering the nursing profession, and understanding the challenges faced by them: Iranian and developed countries' perspectives. Nurs Midwifery Stud. 2013 Dec;2(4):49-56. Disponível em:

https: //www.ncbi.nlm.nih.gov/pmc/articles/PMC4228905/

39 - Sales OP, Bueno BCL, Araújo KEV, Jesus ADF, Guimarães CM. Gênero masculino na enfermagem: estudo de revisão integrativa. Revista Humanidades e Inovação v.5, n. $11-2018$.

40 - Magalhães TTS, Taffner VBN. Dificuldades para a atuação autônoma do enfermeiro obstetra no Brasil. Revista de Divulgação Científica Sena Aires, v. 9, n. 4 (2020). 
41 - Almeida BS. Ariane CM. Aisiane CM. Urbanir SR. Vanuza SC. Wesley AAS. Autonomia percebida pelo enfermeiro obstetra na sala de parto. v. 12 n. 1 (2020): Revista Eletrônica Acervo Saúde (ISSN 2178-2091).

42 - Amorim T, Aline CMA, Eliane MPG, Solange CFD, Helen MG, Candido MCRM. "Percepção de enfermeiras obstetras sobre o modelo e prática assistencial em uma maternidade filantrópica." Revista de Enfermagem da UFSM [Online], 9 (2019): e30. Web. 17 Dez. 2020. Disponível em:

https: //periodicos.ufsm.br/reufsm/article/view/34868

43 - Amaral Rosangela da Conceição Sant'anna, Alves Valdecyr Herdy, Pereira Audrey Vidal, Rodrigues Diego Pereira, Silva Luana Asturiano da, Marchiori Giovanna Rosário Soanno. A inserção da enfermeira obstétrica no parto e nascimento: obstáculos em um hospital de ensino no Rio de Janeiro. Esc. Anna Nery [Internet]. 2019 [cited 2020 Dec 17] ; 23( 1 ): e20180218. Disponível em: http:// www.scielo.br/scielo.php?script=sci_arttext\&pid=S1414$81452019000100222 \& \operatorname{lng}=e n$

44 - Conselho Federal de Enfermagem (Cofen). Parecer n. 17, de 11 de novembro de 2010. Trata-se de encaminhamento dos documentos em epígrafe pela Secretaria do Cofen, para análise e emissão de Parecer sobre a "viabilidade dos Enfermeiros realizarem procedimentos com Medicamentos e Insumos para Planejamento Familiar Reprodutivo" [Internet]. In: Conselho Federal de Enfermagem. Brasília: Cofen; 2010[cited 2018 Mar 20]. Disponível em: http://www.cofen.gov.br/parecern-172010-cofen-ctln_6148.html

45 - Trigueiro TH, Ferrari JC, Souza SRRK, Wall ML, Barbosa R. Acompanhamento da inserção de dispositivos intrauterinos de cobre por enfermeiros e médicos: estudo longitudinal prospectivo. Rev. Bras. Enferm. [Internet]. 2020 [cited 2020 Dec 16]; 73( Suppl 4): e20200156. Disponível em:

http: / / www.scielo.br/scielo.php?script=sci_arttext\&pid=S003471672020001600199\&lng=en 


\section{CONSIDERAÇÕES FINAIS}

Considerando o processo de formação profissional em serviço proposto pela Residência Multiprofissional em Saúde, especificamente o Programa de Enfermagem Obstétrica do HCPA, a contribuição deste trabalho se dá pela análise crítica da produção científica a respeito do que se espera das competências profissionais do especialista em enfermagem obstétrica. Os achados nesta revisão podem servir de base para reformulações no programa de residência tanto no que diz respeito aos conteúdos abordados em aulas teóricas, quanto às oportunidades práticas que subsidiam a formação de competência técnica dos profissionais envolvidos nessa modalidade de formação. Permitir que profissionais sem competência profissional adequada atuem em seus campos de prática aumenta riscos para segurança do paciente, influencia de forma negativa na confiança pública na profissão e nos sistemas de saúde mundialmente e ainda prejudica indicadores de qualidade na assistência materna e neonatal (YGZAW ET AL, 2015). Portanto, qualificar a atenção materna e neonatal no Brasil, assim como os desfechos relacionados à assistência justificam a necessidade de fortalecimento de programas de formação profissional, atualização de instrutores em obstetrícia e articulação de programas teóricos com oportunidades práticas que proporcionem o desenvolvimento de habilidades para a atuação autônoma como enfermeiras obstetras.

Quando se considera a realidade de atuação de profissionais formados por programas de residência e o objetivo de formação para o trabalho no Sistema Único de Saúde, é importante que trabalhos científicos sejam conduzidos com o objetivo de aprimorar as práticas de atenção ao parto e nascimento e que tenham como consequência a melhora no cuidado prestado aos usuários do sistema público de saúde. Considerando os achados na revisão e o atual cenário de atuação de enfermeiras obstétricas no Brasil, cabe a possibilidade de ampliação futura da atuação dessas profissionais, seguindo o exemplo de países onde a atuação abrange o manejo em situações de abortamento e realização de ultrassonografias, por exemplo. A atuação abrangente de enfermeiras obstétricas demanda mudanças nos cenários onde estes profissionais atuam, que devem ser respaldadas por legislação específica, bem como envolver gestores da saúde com a finalidade de operacionalizar a mudança no modelo assistencial.

Dentre as limitações deste estudo podemos considerar as características metodológicas dos estudos incluídos na análise: estudos observacionais, na maioria de recorte transversal ou qualitativos. Estes desenhos de pesquisas não permitem a generalização dos resultados, apenas a geração de hipóteses a partir dos dados encontrados. Outra fragilidade do estudo é a variedade de categorias profissionais envolvidas na assistência ao parto que compuseram as amostras nos 
estudos analisados, marcando a heterogeneidade dos profissionais envolvidos na assistência, bem como do processo de formação e avaliação dos mesmos.

Além dos aspectos relevantes para a formação na modalidade de Residência Multiprofissional em Saúde que surgiram na discussão deste trabalho, cabe ainda a possibilidade de estudos futuros que avaliem a situação atual de cursos de formação em enfermagem obstétrica, a forma de avaliação de competência profissional utilizada nos diferentes cenários e quais as implicações para assistência em cenário real da qualidade de formação desses profissionais. 


\title{
REFERÊNCIAS
}

\author{
ASSOCIAÇÃO BRASILEIRA DE OBSTETRIZES E ENFERMEIROS OBSTETRAS - \\ ABENFO. Competências essenciais para o exercício básico da obstetrícia/2002/ICM \\ (traduzido para o português). Disponível em: \\ $<$ https://www.abenfo.org.br/site/biblioteca/arquivos/manuais/116.pdf>. Acesso em 01 out \\ 2019.
}

AMARAL, Rosangela da Conceição Sant'anna et al. A enfermagem obstétrica e sua interface com o modelo obstétrico brasileiro. Revista Enfermagem Atual InDerme, v. 87, n. 25, 11 abr. 2019.

AMORIM, Torcata; GUALDA, Dulce Maria Rosa. Coadjuvantes das mudanças no contexto do ensino e da prática da enfermagem obstétrica. Rev Rene, Fortaleza, 2011 out/dez; 12(4):833-40. Disponível em: <http://periodicos.ufc.br/rene/article/view/4352/3336>. Acesso em 19 set 2019.

BERNARDO, Wanderley Marques; NOBRE, Moacyr Roberto Cuce; JATENE, Fábio Biscegli. A prática clínica baseada em evidências: parte II - buscando as evidências em fontes de informação. Rev. Assoc. Med. Bras., São Paulo, v. 50, n. 1, p. 104-108, 2004. Disponível em: <http://www.scielo.br/scielo.php?script=sci_arttext\&pid=S0104-

$42302004000100045 \& \operatorname{lng}=$ en\&nrm=iso>. Acesso em 12 out 2019.

BOGREN, Malin; ROSENGREN, Josefin; ERLANDSSON, Kerstin. Build professional competence and Equip with strategies to empower midwifery students - An interview study evaluating a Simulation-based learning course for midwifery educators in Bangladesh. Nurse Educ Pract; 35: 27-31, 2019 Feb. Disponível em: $<$ Https://www.sciencedirect.com/science/article/pii/S1471595318306346>. Acesso em $15 \mathrm{dez}$ 2020.

BRASIL. Ministério da Educação. Ministério da Saúde. Portaria Interministerial MEC/MS no 1.077 de 12 de novembro de 2009. Brasília, 2009. Disponível em:

$<$ http://portal.mec.gov.br/index.php?option=com_docman\&view=download\&alias=15462por-1077-12nov-2009\&Itemid=30192> . Acesso em 22 set 2019.

BRASIL. Ministério da Saúde. Comissão Nacional de Incorporação de Tecnologias no SUS. Relatório de Recomendação - Diretriz Nacional de Assistência ao Parto Normal. Brasília, 2016. Disponível em: <http://conitec.gov.br/images/Consultas/2016/Relatorio_DiretrizPartoNormal_CP.pdf>. Acesso em 19 set 2019.

Conselho Nacional de Saúde. Resolução nº 466, de 12 de dezembro de 2012. Dispõe sobre diretrizes e normas regulamentadoras de pesquisas envolvendo seres humanos [online]. Disponível em <http://conselho.saude.gov.br/resolucoes/2012/Reso466.pdf>. Acesso em 12 set 2019.

Humanização do parto e do nascimento / Ministério da Saúde. Universidade Estadual do Ceará. - Brasília, 2014. 465 p.: il. - (Cadernos HumanizaSUS; v.4). 
Secretaria de Atenção à Saúde. Departamento de Ações

Programáticas e Estratégicas. Coordenação-Geral de Saúde das Mulheres. Coordenação-Geral de Saúde da Criança e Aleitamento Materno. Apice On - Aprimoramento e Inovação no Cuidado e Ensino em Obstetrícia e Neonatologia. Brasília, 2017. Disponível em: <http://portalarquivos.saude.gov.br/images/pdf/2017/agosto/18/Apice-On-2017-08-11.pdf> Acesso em 25 set 2019.

setembro de 1998. Disponível em:

Secretaria de Assistência à Saúde. Portaria no 163 de 22 de <http://www.abenforj.com.br/site/arquivos/outros/Portaria\%20163.pdf >. Acesso em 08 out 2019.

BRASIL. Presidência da República. Casa Civil. Subchefia de assuntos jurídicos. Lei nº 7.498, de 25 de Junho de 1986. Brasília, 1986. Disponível em:

<http://www.planalto.gov.br/ccivil_03/Leis/L7498.htm>. Acesso em 20 set 2019.

CAUS, Eliz Cristine Maurer et al . O processo de parir assistido pela enfermeira obstétrica no contexto hospitalar: significados para as parturientes. Esc. Anna Nery, Rio de Janeiro, v. 16, n. 1, p. 34-40, Mar. 2012. Disponível em:

$<$ http://www.scielo.br/scielo.php?script=sci_arttext\&pid=S1414-

$81452012000100005 \& \operatorname{lng}=$ en\&nrm=iso>. Acesso em 13 out 2019.

CHATUVERDI, Sarika; UPADHYAY, Sourabh; DE COSTA, Ayesha. Competence of birth attendants at providing emergency obstetric care under India's JSY conditional cash transfer program for institutional delivery: an assessment using case vignettes in Madhya Pradesh province. BMC Pregnancy Childbirth, 14, 174 (2014). Disponível em:

<https://bmcpregnancychildbirth.biomedcentral.com/articles/10.1186/1471-2393-14-174>. Acesso em 15 dez 2020.

CINTRA, Nayara Ruiz; RIESCO, Maria Luiza Gonzalez. Caracterização dos cursos de graduação em Obstetrícia em países da América do Sul. Interface (Botucatu), Botucatu , v. 23, e180505, 2019. Disponível em:

<http://www.scielo.br/scielo.php?script=sci_arttext\&pid=S1414-

$32832019000100279 \& \operatorname{lng}=\mathrm{en} \& \mathrm{nrm}=\mathrm{iso}>$. Acesso em 01 out 2019.

COFEN. Conselho Federal de Enfermagem. Resolução COFEN nº 0477/2015. Dispõe sobre a atuação de Enfermeiros na assistência às gestantes, parturientes e puérperas. Disponível em: <http://www.cofen.gov.br/resolucao-cofen-no-04772015_30967.html/print/>. Acesso em 08 out 2019.

CUNHA, Margarida de Aquino et al . Assistência pré-natal: competências essenciais desempenhadas por enfermeiros. Esc. Anna Nery, Rio de Janeiro, v. 13, n. 1, p. 145-153, Mar. 2009. Disponível em:

<http://www.scielo.br/scielo.php?script=sci_arttext\&pid=S1414-

$81452009000100020 \& \operatorname{lng}=$ en\&nrm=iso>. Acesso em 28 set 2019.

DATASUS. Secretaria de atenção à saúde. Cadastro nacional dos estabelecimentos em saúde - CNESNet, 2019. Disponível em:

<http://cnes2.datasus.gov.br/Mod_Ind_Leitos_Listar.asp?VCod_Leito=10\&VTipo_Leito=4\& VListar $=1 \&$ VEstado=43\&VMun=\&VComp=>. Acesso em 20 set 2019. 
DIAS, Marcos Augusto Bastos; DOMINGUES, Rosa Maria Soares Madeira. Desafios na implantação de uma política de humanização da assistência hospitalar ao parto. Ciênc. saúde coletiva, Rio de Janeiro, v. 10, n. 3, p. 699-705, Set. 2005. Disponível em: $<$ http://www.scielo.br/scielo.php?script=sci_arttext\&pid=S1413$81232005000300026 \& \operatorname{lng}=$ en\&nrm=iso> . Acesso em 22 set 2019.

DOWNE, Soo; FINLAYSON, Kenneth Willian; FLEMING, Anita. Creating a Collaborative Culture in Maternity Care. Journal of Midwifery \& Women's Health. Volume 55, Issue 3, May-June 2010, Pages 250-254. Disponível em: <https://www.sciencedirect.com/science/article/pii/S152695231000005X?via\%3Dihub\#!>. Acesso em 01 out 2019.

FERTONANI, Hosanna Pattrig et al . Modelo assistencial em saúde: conceitos e desafios para a atenção básica brasileira. Ciênc. saúde coletiva, Rio de Janeiro , v. 20, n. 6, p. 1869-1878, June 2015 . Disponível em: <http://www.scielo.br/scielo.php?script=sci_arttext\&pid=S1413$81232015000601869 \& \operatorname{lng}=$ en\&nrm=iso $>$. Acesso em 26 set 2019.

GOSHU, Miruts et al. Assessing the competence of midwives to provide care during labor, childbirth and the immediate postpartum period - A cross sectional study in Tigray region, Ethiopia. PLoS One. 2018 Oct 31;13(10):e0206414. Disponível em: <https://journals.plos.org/plosone/article?id=10.1371/journal.pone.0206414>. Acesso em 15 $\operatorname{dez} 2020$.

HOSPITAL DE CLÍNICAS DE PORTO ALEGRE - HCPA. Prestação de contas ordinárias anual. Relatório de gestão e administração do exercício de 2017. Fevereiro, 2018. Disponível em < https://www.hcpa.edu.br/downloads/relatoriogestao.pdf>. Acesso em 18 set 2019.

INTERNATIONAL CONFEDERATION OF MIDWIVES - ICM. Annual Report 2018. The Hague, 2018. Disponível em: <https://www.internationalmidwives.org/assets/files/generalfiles/2019/07/icm_annualreport2018_eng_download.pdf>. Acesso em 01 out 2019.

Midwifery Practice - 2019 update. ICM, 2019. Disponível em: Essential Competencies for $<$ https://www.internationalmidwives.org/our-work/policy-and-practice/essentialcompetencies-for-midwifery-practice.html>. Acesso em 01 nov 2020.

JONAH. Journal of Nursing and Health. Submissões online - Guia para autores, agosto de 2020. Acesso em 20 dez 2020. Disponível em:

$<$ https://periodicos.ufpel.edu.br/ojs2/index.php/enfermagem/about/submissions\#authorGuideli nes>.

JONES, Ricardo Herbert. Atenção humanizada ao parto e nascimento. Agência Nacional de Saúde Suplementar (Brasil). O modelo de atenção obstétrica no setor de Saúde Suplementar no Brasil: cenários e perspectivas. Rio de Janeiro, 2008.

KAK, Neeraj; BURKHALTER, Bart; COOPER, Mary-Ann. Measuring the competence of healthcare providers. Operations Research Issue Paper 2. Bethesda, MD: Published for the U.S. Agency for International Development (USAID) by the Quality Assurance (QA) Project. 2001. Disponível em: 
<https://www.usaidassist.org/sites/assist/files/measuring_the_competence_of_hc_providers_q ap_2001.pdf>. Acesso em 01 out 2019.

KIBWANA, Sharon et al. Trainers' perception of the learning environment and student competency: A qualitative investigation of midwifery and anesthesia training programs in Ethiopia. Nurse Educ Today. 2017 Aug;55:5-10. Disponível em:

<https://pubmed.ncbi.nlm.nih.gov/28505523/>. Acesso em $15 \mathrm{dez} 2020$.

LOHELA, Terhi Johanna et al. Competence of health workers in emergency obstetric care: an assessment using clinical vignettes in Brong Ahafo region, Ghana. BMJ Open. 2016 Jun 13;6(6):e010963. Disponível em: <https://bmjopen.bmj.com/content/6/6/e010963>. Acesso em 15 dez 2020.

MENDES, Karina Dal Sasso; SILVEIRA, Renata Cristina de Campos Pereira; GALVAO, Cristina Maria. Revisão integrativa: método de pesquisa para a incorporação de evidências na saúde e na enfermagem. Texto contexto - enferm., Florianópolis , v. 17, n. 4, p. 758-764, Dec. 2008. Disponível em:

<http://www.scielo.br/scielo.php?script=sci_arttext\&pid=S0104-

07072008000400018\&lng=en\&nrm=iso>. Acesso em 18 abr 2020.

MINAYO, Maria Cecília de Souza. O desafio do conhecimento: pesquisa qualitativa em saúde. 14 ed. - Hucitec. São Paulo: Hucitec; 2014.

MPELI, Moliehi. Analysis of self-evaluated ethical competence of midwifery students at a selected nursing college in the Free State. Curationis. 2018 Aug 29;41(1):e1-e9. Disponível em: <https://pubmed.ncbi.nlm.nih.gov/30198296/>. Acesso em 15 dez 2020.

NARCHI, Nádia Zanon. Análise do exercício de competências dos não médicos para atenção à maternidade. Saude soc., São Paulo , v. 19, n. 1, p. 147-158, Mar. 2010. Disponível em: $<$ http://www.scielo.br/scielo.php?script=sci_arttext\&pid=S0104$12902010000100012 \& \operatorname{lng}=$ en\&nrm=iso $>$. Acesso em 28 set 2019.

NETSHISAULO, Khathustselo; MAPUTLE, Maria. Expected clinical competence from midwifery graduates during community service placement in Limpopo province, South Africa. Health SA. 2018 Nov 29;23:1166. Disponível em:

<https://www.ncbi.nlm.nih.gov/pmc/articles/PMC6917449/>. Acesso em 15 dez 2020.

OBSERVAPOA. Prefeitura Municipal de Porto Alegre. Porto Alegre em Análise: sistema de gestão e análise de indicadores. Porto Alegre, 2018. Disponível em:

<http://portoalegreemanalise.procempa.com.br/?regiao=1_1_99>. Acesso em 20 set. 2019.

OMS. Organização Mundial de Saúde. Declaração da OMS sobre Taxas de Cesáreas. 2015. Disponível em:

<http://apps.who.int/iris/bitstream/10665/161442/3/WHO_RHR_15.02_por.pdf>. Acesso em 20 set 2019.

OPAS. Organização Panamericana da Saúde. Centro latino-americano de Perinatologia. Conjunto de ferramentas para o fortalecimento da obstetrícia: desafios e contribuições para a formação em obstetrícia no Brasil, 2013. Disponível em: <https://www.paho.org/clap/index.php?option=com_docman\&view=download\&alias=434- 
conjunto-de-ferramentas-para-o-fortalecimento-da-parteria-nas-americas-

$3 \&$ category_slug=salud-de-mujer-reproductiva-materna-y-perinatal \&Itemid=219\&lang=es $>$. Acesso em 08 out 2019.

PARENTI, Patricia Wottrich et al. Cuidado pré-natal às adolescentes: competências das enfermeiras [Internet]. Revista Baiana de Enfermagem. 2012 ; 26( 2): 498-509. Disponível em: <https://periodicos.ufba.br/index.php/enfermagem/article/view/6534>. Acesso em $15 \mathrm{dez}$ 2020 .

RABELO, Leila Regina; OLIVEIRA, Dora Lúcia de. Percepções de enfermeiras obstétricas sobre sua competência na atenção ao parto normal hospitalar. Rev. esc. enferm. USP, São Paulo, v. 44, n. 1, p. 213-220, Mar. 2010. Disponível em:

$<$ http://www.scielo.br/scielo.php?script=sci_arttext\&pid=S0080-

62342010000100030\&lng=en\&nrm=iso>. Acesso em 01 ago 2020.

RIESCO, Maria Luiza Gonzalez; FONSECA, Rosa Maria Godoy Serpa da. Elementos constitutivos da formação e inserção de profissionais não-médicos na assistência ao parto.

Cad. Saúde Pública, Rio de Janeiro, v. 18, n. 3, p. 685-698, June 2002 . Disponível em: $<$ http://www.scielo.br/scielo.php?script=sci_arttext\&pid=S0102-

311X2002000300012\&lng=en\&nrm=iso>. Acesso em 22 set 2019.

ROTHER, Edna Terezinha. Revisão sistemática X revisão narrativa. Acta paul. enferm., São Paulo , v. 20, n. 2, p. v-vi, June 2007. Disponível em:

$<$ http://www.scielo.br/scielo.php?script=sci_arttext\&pid=S0103-

$21002007000200001 \& \operatorname{lng}=$ en\&nrm=iso>. Acesso em 12 out 2019.

SOUZA, Kellcia Rezende; KERBAUY, Maria Teresa Micelli. Abordagem quanti-qualitativa: superação da dicotomia quantitativa-qualitativa na pesquisa em educação. EDUCAÇÃ̃O E FILOSOFIA, v. 31, n. 61, p. 21-44, 27 abr. 2017.

UFMG. Caderno do Curso de Aprimoramento em Enfermagem Obstétrica com foco na atenção ao parto e nascimento: qualificação dos processos de cuidado e de gestão (CAEO/PN/APICEON) / organizado por Kleyde Ventura de Souza [et al.] -- Belo Horizonte: Escola de Enfermagem da UFMG, 2019. Disponível em:

<http://portaldeboaspraticas.iff.fiocruz.br/apice/wp-

content/uploads/2019/04/caderno_Curso_Aprimoramento_Enfermeiras_Obst\%C3\%A9tricas. pdf>. Acesso em 22 set 2019.

UFRGS. Hospital de Clínicas de Porto Alegre. Principais números: produção assistencial 2017 e 2018 (texto da Internet). Porto Alegre, 2019. Disponível em: <

https://www.hcpa.edu.br/institucional/institucional-apresentacao/institucional-apresentacaoprincipais-numeros $>$. Acesso em 25 set 2019.

UFRGS. Hospital de Clínicas de Porto Alegre. Programa de Residência em Enfermagem Obstétrica. Porto Alegre, 2017.

Métodos de pesquisa / [organizado por] Tatiana Engel Gerhardt e Denise Tolfo Silveira ; coordenado pela Universidade Aberta do Brasil - UAB/UFRGS e pelo Curso de Graduação Tecnológica - Planejamento e Gestão para o Desenvolvimento Rural da SEAD/UFRGS. - Porto Alegre: Editora da UFRGS, 2009. 
VARGENS, Octavio Muniz da Costa; SILVA, Alexandra; PROGIANTI, Jane Márcia. Noninvasive nursing technologies for pain relief during childbirth-The Brazilian nurse midwives' view. Midwifery, v. 29, n. 11, p. e99-e106, 2013.

VOGT, Sibylle Emilie; SILVA, Kátia Silveira da; DIAS, Marcos Augusto Bastos. Comparação de modelos de assistência ao parto em hospitais públicos. Rev. Saúde Pública, São Paulo, v. 48, n. 2, p. 304-313, Abr. 2014. Disponível em $<$ http://www.scielo.br/scielo.php?script=sci_arttext\&pid=S003489102014000200304\&lng=en\&nrm=iso>. Acesso em 20 Dec. 2020.

WHO. World Health Organization. Making pregnancy safer: the critical role of the skilled attendant: a joint statement by WHO, ICM and FIGO. Geneva, 2004. Disponível em: <https://apps.who.int/iris/bitstream/handle/10665/42955/9241591692.pdf?sequence=1\&isAllo wed=y>. Acesso em 29 set 2019.

YIGZAW, Tegbar et al. How well does pre-service education prepare midwives for practice: competence assessment of midwifery students at the point of graduation in Ethiopia. BMC Med Educ, 15, 130 (2015). Disponível em:

$<$ https://bmcmededuc.biomedcentral.com/articles/10.1186/s12909-015-0410-6>. Acesso em $15 \operatorname{dez} 2020$. 


\section{APÊNDICES}

APÊNDICE A - Formulário para avaliação dos estudos:

\begin{tabular}{|c|c|c|}
\hline \multicolumn{3}{|c|}{ Dados de identificação } \\
\hline \multicolumn{3}{|l|}{ Título: } \\
\hline \multicolumn{3}{|l|}{ Autores: } \\
\hline Periódico: & Ano de publicação: & Volume/número: \\
\hline \multicolumn{3}{|c|}{ Descritores: } \\
\hline \multicolumn{3}{|l|}{ Objetivos: } \\
\hline \multicolumn{3}{|c|}{ Metodologia } \\
\hline \multicolumn{3}{|c|}{ Tipo de estudo: } \\
\hline \multicolumn{3}{|c|}{ Amostra/população: } \\
\hline \multicolumn{3}{|c|}{ Local/campo de estudo: } \\
\hline \multicolumn{3}{|c|}{ Coleta de dados: } \\
\hline \multicolumn{3}{|c|}{ Resultados } \\
\hline \multicolumn{3}{|c|}{ Conclusões } \\
\hline
\end{tabular}

Fonte: Cunha, 2020. 